
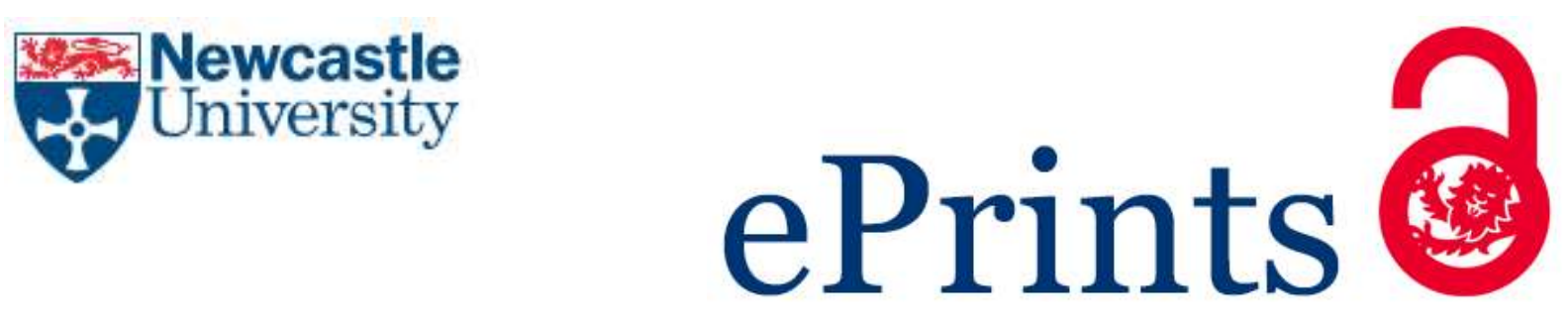

Kamihiro S, Stergiadis S, Leifert C, Eyre M, Butler G. Meat quality and health implications of organic and conventional beef production. Meat Science 2015, 100, 306-318.

\title{
Copyright:
}

(C) 2015. This manuscript version is made available under the CC-BY-NC-ND 4.0 license

DOI link to article:

http://dx.doi.org/10.1016/j.meatsci.2014.10.015

Date deposited:

$08 / 02 / 2018$

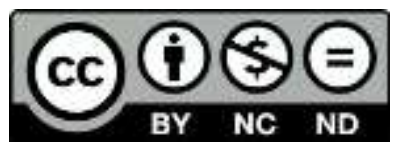

This work is licensed under a

Creative Commons Attribution-NonCommercial-NoDerivatives 4.0 International licence 


\section{Meat quality and health implications of organic and conventional beef production}

Kamihiro, S. ${ }^{\mathrm{a}}{ }$, Stergiadis, S. ${ }^{\mathrm{a} 2}$, Leifert, C. ${ }^{\mathrm{a}}$, Eyre, M. D. ${ }^{\mathrm{a}}$, and Butler, G. ${ }^{* a}$

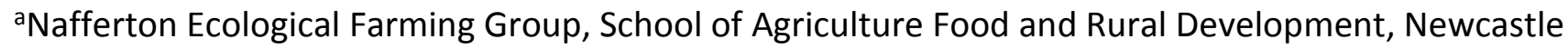
University, Nafferton Farm, Stocksfield, Northumberland, NE43 7XD, UK

\section{Abstract}

Recommendation to reduce fat consumption from ruminant meat does not consider the contribution of nutritionally beneficial fatty acids in lean beef. Here we report effects of production system (organic vs conventional) and finishing season on meat and fat quality of sirloin steaks from retail outlets and simulated fatty acid intakes by consumers. There was little difference in meat quality $(\mathrm{pH}$, shear force and colour), but the fat profiles varied considerably between production systems and season. Meat fat from organic and summer finished cattle contained higher concentrations of conjugated linoleic acid, its precursor vaccenic acid and individual omega- 3 fatty acids and had a lower ratio of omega- 6 to omega-3 fatty acids compared with non-organic and winter finished cattle respectively. The fat profile from summer finished organic beef aligns better to recommended dietary guideline including those for long chain omega-3 fatty acids compared with that from winter finished, non-organic steak. Key words: beef quality, fatty acid intake, organic, conventional

Paper published in Meat Science:

https://www.sciencedirect.com/science/article/pii/S0309174014004537

\footnotetext{
${ }^{1}$ Permanent address: Animal Health Division, Food Safety and Consumers Affairs Bureau, Ministry of Agriculture, Forestry and Fisheries of Japan, 1-2-1 Chiyoda-ku, Tokyo, 100-8950, Japan

${ }^{2}$ Current address: Sustainable Agri-Food Sciences Division, Agriculture Branch, Agri-Food and Biosciences Institute, Large Park, Hillsborough, Co Down, BT26 6DR, UK

*Corresponding Author: gillian.butler@ncl.ac.uk, Nafferton Ecological Farming Group, School of Agriculture Food and Rural Development, Newcastle University, Nafferton Farm, Stocksfield, Northumberland, NE43 7XD, UK, phone: 00 (44) 1661830 222, fax: 00 (44) 1661831006
} 


\section{Introduction}

Dietary fat impacts, both positively and negatively, on human health. The role of fat and fatty acids (FA) composition has been reviewed frequently and proposals made for optimum fat profiles and contribution of various foods to achieve a balance of individual FA appropriate for our health. The FAO paper 91 on fats and fatty acids in human nutrition (Food and Agriculture Organisation of the United Nations, 2010) provides a relatively recent consensus on acceptable guidelines. Whilst a maximum of $35 \%$ of energy intake from fat is the recognised upper limit, a minimum dietary contribution of 15-20 $\%$ is also important for health to ensure sufficient energy, fat soluble antioxidants and vitamins and essential FA intake. The FAO report and recent European Food Safety Authority (EFSA) opinion (European Food Safety Authority, 2010) considers individual FA rather than total fat consumption or groups such as saturated fatty acids (SFA). Recommendations for omega-3 polyunsaturated fatty acids ( $n$-3) differentiate between $\alpha$-linolenic acid (C18:3 n-3, ALA) and its longer chain derivatives eicosapentaenoic acid (C22:5 n-3, EPA) and docosahexaenoic acid (C22:6n-3, DHA). EFSA considers ALA intakes to be satisfactory, but suggests increased consumption of $n-3$ longer chain ( $n-3$ LC). In contrast to $n-3$, omega- 6 polyunsaturated fatty acid (n-6) recommendations focus on total $n-6$ intake (=Linoleic acid [C18:2 c9,12, LA] plus its longer chain products including arachidonic acid[20:4 n-6, AA]). There is agreement about the role of $n-3$ in reducing inflammation and risk of chronic conditions such as heart disease (Calder, 2004), although n-3 are highly concentrated in brain and nerve tissue and also appear important for cognitive and behavioural function (Ruxton, Reed, Simpson, \& Millington, 2007). Oily fish is acknowledged as an important source for n-3 particularly EPA and DHA, but there are concerns about increasing oily fish consumption, with respect to sustainability (pressure on declining fish stocks (Food and Agriculture Organization of the United Nations: Fisheries and Aquaculture Department, 2012)) and contamination (fish consumption can be associated with heavy metals such as mercury (N. D. Scollan, Kim, E.J., Lee, M.R.F., Whittington, F., and Richardson, R.I. , 2008; Williams \& Burdge, 2006)). While the absolute content of $n-3$, especially $n-3$ LC in beef and other red meat is less than oily fish $(0.28-0.52 \mathrm{mg}$ vs $19.9 \mathrm{mg} / \mathrm{g})$, it is considered to be an important source of n-3 LC in Western countries (Howe, Meyer, Record, \& Baghurst, 2006; McAfee, et al., 2011; Meyer, et al., 2003). Howe et al. (2006) estimated meat would provide approximately half the total dietary intake of n-3 LC in Australian diet, of which beef was estimated to be the greatest contributor (23.3 $\%)$.

Whilst beef provides essential fatty acid LA and ALA and other beneficial FA including conjugated linoleic acid (CLA), oleic acid and n-3 LC, it also has high concentrations of saturated fatty acids linked to cardiovascular disease and colon cancer risks (McAfee, et al., 2010; N. Scollan, et al., 2006). Excess 
fat consumption might be related to chronic diseases such as coronary heart disease, diabetes and cancers (Committee on Medical Aspects of Food Policy, 1984), but the actual fat content of lean beef from roughage-based production is known to be low at 2-5 \% (N. Scollan, et al., 2006) and beef contributes only $4 \%$ of total daily fat intake in UK (UK Department of Health, 2008). Ruminant milk and meat are sole dietary sources of CLA, which has been linked to a range of health benefits in vitro and in animal studies; reduced risk of cardiovascular disease and certain cancers. However, because of the current lack of dietary intervention or cohort studies showing significant benefits of CLA in Man, there are no recognised dietary guidelines for CLA intake (Bhattacharya, Banu, Rahman, Causey, \& Fernandes, 2006).

Meat fat composition has been extensively studied, aiming to understand the mechanism to elevate n-3 LC and CLA concentrations and/or reduce SFA, which tend to dominate ruminant fat, as a consequence of dietary polyunsaturated fatty acids (PUFA) being hydrogenated/ or saturated by microbial populations in the rumen. Fatty acids are deposited as structural phospholipids in cell and organelle membranes as well as neutral lipids in intramuscular fat (IMF) resulting in marbling between fibres within muscles, inter-muscular fat (between different muscles) and subcutaneous fat (SCF). Partitioning of fat between these depots and the fatty acid profiles in carcass joints are extremely variable and influenced by genetics, age, sex, feeding regimes and butchering techniques (Raes, De Smet, \& Demeyer, 2004; N. Scollan, et al., 2006; Wood, et al., 2008). Subcutaneous fat is primarily an energy store or in some circumstances for insulation, with little priority for specific fatty acids, in contrast to lipid accretion within muscles, where young and/or lean animals preferentially accumulate long chain PUFA in phospholipids to ensure cellular fluidity, metabolism and function. PUFA concentrations tend to be consistently high within phospholipids, although they become diluted with more saturated FA and neutral lipid triglycerides as cattle age and/or become fatter and accumulate greater IMF. On average beef IMF consists of 45-48 \% SFA, 35-45 \% monounsaturated fatty acid (MUFA) and about 5 \% PUFA (N. Scollan, et al., 2006), typically with PUFA:SFA ratio of 0.11 (Wood, et al., 2008). Subcutaneous fat typically has a lower PUFA content and PUFA:SFA ratio (0.05) (Wood, et al., 2008) although potentially, this is of less consequence to human health, since it can be trimmed or avoided rather than eaten.

Initiatives to improve beef fat composition typically centre around forage feeding or supplementation with oil seeds rich in PUFA - aiming to increase ALA (and to a lesser extent LA) intake by cattle, reduce rumen hydrogenation and hence provide precursors for elongation and/or desaturation into n-3 LC and CLA in the adipose tissue (Daley, Abbott, Doyle, Nader, \& Larson, 2010; N. Scollan, et al., 2006). The preferential fat composition of beef raised on forage diets is well documented, as is the benefit of 
grazing cattle on pasture, rather than using conserved forage (French, et al., 2000; Kraft, Kramer, Schoene, Chambers, \& Jahreis, 2008; Warren, et al., 2008) Although there are virtually no studies into the impact of grass- or forage-based meat consumption on long term impacts on human health, a recent diet intervention study (McAfee, et al., 2011) assessed grass-fed red meat consumption on n-3 LC levels in volunteers. Eating grass-fed beef and lamb for 4 weeks increased plasma and platelet $n-3$ LC (DHA and EPA) compared to those provided with equal amounts of meat from silage and concentrate-feed regimes. Unfortunately, in many regions feeding fresh forage to cattle is not a yearround option; excesses in temperature and/or precipitation limit herbage growth and/or utilisation, resulting in seasonal fluctuation in animal product quality as livestock change from storage diets to grazing (Butler, Stergiadis, Seal, Eyre, \& Leifert, 2011; Fredriksson Eriksson \& Pickova, 2007; Pestana, et al., 2012). However, whilst the science behind enhancing meat fat is understood, from the consumers' perspective, there is no quality assurance schemes defining 'forage fed cattle' and hence confidence in product quality. To date the only legal designation on meat that might indicate enhanced fatty acid profiles are certain Protected Designation of Origin (PDO) specifications such as Mertolenga (Alfaia, Quaresma, et al., 2006) or Portuguese Carnalentejana (Alfaia, Ribeiro, et al., 2006). An alternative assurance mechanism might be organic certification, since European organic standards (European Commission, 2008) require cattle to be fed whole milk until at least 12 weeks of age and maximise use of pasture throughout their lives (for cows as well as growing cattle) with a minimum of $60 \%$ of their dry matter intake from forage. Although, organic lamb and milk have been shown to contain significantly higher concentrations of nutritionally desirable fatty acids and/or antioxidants (Angood, et al., 2008; Butler, et al., 2011; Ellis, et al., 2006), there are virtually no studies comparing the composition of organic and conventionally produced retail beef, with the exception of a paper by Razminowicz, Kreuzer, and Scheeder (2006).

This study quantifies the effect of production systems (organic vs conventional) and finishing season on selected nutritional and sensory quality parameters (including simulated eating quality and fatty acid profiles of intramuscular fat, subcutaneous fat and the consequences of trimming the latter of beef available to consumers in the North East of England.

\section{Materials and methods}

\subsection{Sampling}

Organic and non-organic beef sirloin steaks were purchased from 2 major retail chains (designated $A$ and $B$ ) in North East England on 5 occasions (to avoid selecting more than 1 pack from any 1 animal) in April (between 5 and 16 of April) and again in October (between 11 and 29 of October) 2011. Meat 
purchased in April and October was assumed to be winter- and summer-finished, respectively. On each occasion, packs of 2 sirloin steaks were chosen, both assumed to originate from the same animal based on information on product labelling: used-by date, the EC abattoir code, date code and product ID. One pack of conventional beef purchased in April was excluded because labelling was identical to that of a sample purchased 2 days earlier. Product labelling and information on associated web-sites implied all meat originated from 'forage-based production systems' although there was no dietary detail specified.

Samples were transported to the laboratory on icepacks, removed from the original modified atmosphere package and transferred to sealed individual polyethylene bags within 1 hour of purchase and stored at $-20^{\circ} \mathrm{C}$ until further analysis.

\subsection{Meat quality: Sensory Analysis (Colour and Warner-Bratzler Shear Force)}

Weight and thickness of steaks were measured after thawing overnight at $4^{\circ} \mathrm{C}$. A $3 \mathrm{~mm}$ slice from the surface of dorsal part of the muscles longissimus (ML) was bloomed (exposed to air) for 1 hour at $4^{\circ} \mathrm{C}$, used to assess $\mathrm{pH}$ and muscle colour (average of 3 areas on the fresh cut surface) using Chroma Meter (SR-200, Minolta, Japan), applying the L*a*b* system with D65 as light source (Razminowicz, et al., 2006). Steaks were, weighed and cooked in individual polyethylene bags immersed in $70^{\circ} \mathrm{C}$ water for $60 \mathrm{~min}$, then cooled in running water for $30 \mathrm{~min}$ (Cho, Choi, Hwang, Kim, \& Myung, 2006). Cooked steaks were reweighed to calculate cooking losses, and 6 cores (approximately $1.27 \mathrm{~cm}$ diameter) prepared from each, drilling parallel to muscle fibres. Cores were exclusively from ML avoiding other muscles such as multifidus dorsi, seratus doisaris posterior and gluteus medius that can be included in sirloin steaks, depending on the cut position (Jones, et al., 2004). The average force needed to shear replicate cores with a V-shape blade $\left(60^{\circ}\right)$, cross-head speed of $400 \mathrm{~mm} / \mathrm{min}$ using Lloyds Testing Machine (Lloyds Instrument, UK) was taken as Warner-Bratzler Shear Force (WBSF).

\subsection{Preparation of Fatty Acid Methyl Ester (FAME)}

Fatty acid methyl esters (FAME) were prepared after O'Fallon, Busboom, Nelson, and Gaskins (2007). The second steaks from each pack were thawed overnight at $4^{\circ} \mathrm{C}$. Connective tissue, adipose tissue and muscle other than $\mathrm{ML}$ were carefully removed before homogenisation in a food blender and stored in $7 \mathrm{ml}$ plastic vial at $-20^{\circ} \mathrm{C}$. SCF was chopped with scissors, squashed between tweezers and the internal wall of a plastic storage vial $(7 \mathrm{ml})$ and frozen.

Frozen samples ( $1 \mathrm{~g}$ of $\mathrm{ML}$ or $50 \mathrm{mg}$ of SCF) were put into a screw-caped test tubes, to which $1.0 \mathrm{ml}$ of tridecanoic acid (C13:0) internal standard $(0.5 \mathrm{mg} / \mathrm{ml}$ methanol), $0.7 \mathrm{ml}$ of $10 \mathrm{~N} \mathrm{KOH}$ in water and 5.3 $\mathrm{ml}$ of methanol were added. After vortex for 5 second, the tubes were incubated in a water bath (55 
${ }^{\circ} \mathrm{C}$ ) for $1.5 \mathrm{~h}$ with vigorous shaking every $20 \mathrm{~min}$. Tubes were cooled in $-20^{\circ} \mathrm{C}$ freezer for $10 \mathrm{~min}$ and $0.58 \mathrm{ml}$ of $24 \mathrm{~N} \mathrm{H}_{2} \mathrm{SO}_{4}$ in water added before mixing by vortex and returned to the water bath $\left(55^{\circ} \mathrm{C}\right.$ ) for $1.5 \mathrm{~h}$, again with vigorous -shaking every $20 \mathrm{~min}$. After, tubes were cooled in a $-20{ }^{\circ} \mathrm{C}$ freezer for 10 min, $3 \mathrm{ml}$ of hexane was added and mixed thoroughly by a combination of hand-shaking (5 min) and automatic rotating mixer (40 rpm, $5 \mathrm{~min}$ ). After centrifuging for $5 \mathrm{~min}\left(1160 \times \mathrm{g}, 5^{\circ} \mathrm{C}\right), 400 \mu \mathrm{l}$ of the upper hexane layer containing FAME was placed into vials suitable for gas chromatography (GC), capped and stored at $-20^{\circ} \mathrm{C}$ until GC analysis.

\subsection{Fatty Acid Analysis}

Analysis of FAME was carried out with a GC (GC-2014, Shimadzu, Kyoto, Japan) using a Varian CP-SIL 88 fused-silica capillary column (100 m $\times 0.25 \mathrm{~mm}$ internal diameter $\times 0.2 \mu \mathrm{m}$ film thickness). Purified helium was used as a carrier gas with a head pressure of $109.9 \mathrm{kPa}$ and a column flow of $0.43 \mathrm{ml} / \mathrm{min}$. The injection system (Shimadzu AOC-20i) used a split ratio of 50.0 and an injector and flame-ignition detector temperature of $255^{\circ} \mathrm{C}$. One $\mu \mathrm{l}$ of each sample was injected at an internal temperature of 70 ${ }^{\circ} \mathrm{C}$, held constant for $1 \mathrm{~min}$ before being increased to $100{ }^{\circ} \mathrm{C}$ at $5{ }^{\circ} \mathrm{C} / \mathrm{min}$, held for $2 \mathrm{~min}$, and then increased to $160^{\circ} \mathrm{C}$ at $10^{\circ} \mathrm{C} / \mathrm{min}$, where the temperature was held for $90 \mathrm{~min}$, and finally increased to $240^{\circ} \mathrm{C}$ at $5^{\circ} \mathrm{C} / \mathrm{min}$, where the temperature was held for $34 \mathrm{~min}$, giving a total run time of $155 \mathrm{~min}$. A Nu-Chek Prep GLC-463 FAME reference standard (i.e. 52 components) was used to identify and quantify individual FAME in each samples. A relative response factor was calculated for all FAME using C13:0 as the internal standard (Ngeh-Ngwainbi, Lin, \& Chandler, 1997).

\subsection{Calculations and Statistical Analyses}

Meat FA profiles were initially quantified as mg per $100 \mathrm{~g}$ muscle for IMF and as a proportion of total FA (TFA) for SCF. However to allow comparison, FA concentrations in IMF were also computed to a proportion of total FA and results subsequently related to FA profiles in SCF to give the ratio of concentrations between the 2 fat deposits. To evaluate implications of this study for human health, theoretical intakes of nutritionally relevant FA were simulated. Although consumers might avoid eating any or all visible fat, at least some exuded fat from the adipose tissue is likely to be consumed; hence a serving of $10 \mathrm{~g}$ fatty acids from subcutaneous fat was added to $225 \mathrm{~g}$ muscle in this calculation.

Analyses of variance (ANOVA) for $\mathrm{pH}$, colour, WBSF, FA data in IMF and SCF and their ratios were derived from linear mixed effects models using the NLME package in the R statistical environment ( $R$ Development Core Team, 2009). Fixed factors were "supermarket" (A, B), "management system" (organic, non-organic), and "season" (summer-finished, winter-finished), whilst animal ID (different packs) was the random factor. Any values expressed as proportions were arcsine transformed. 
Residuals were checked for normality using the QQNORM function in R (Crawley, 2007) with no deviation found. The relationships between concentrations of individual FA in IMF as well as the ratio of FA concentrations between IMF and SCF against the total FA content of IMF were tested using Pearson product-moment correlations. All analyses were carried out in R and, although proportional FA concentrations were arcsine transformed before ANOVA, all values presented are untransformed.

\section{Results}

The vast majority of differences discussed in this section are statistically significant $(p<0.05)$ although this is not repeated throughout the text, any results mentioned where this is not the case, are declared.

\subsection{Meat quality}

Assessment of meat quality revealed little variation between shops, systems or seasons with the exceptions of steak $\mathrm{pH}$ and weight. Statistically $\mathrm{pH}$ differed significantly between supermarkets ( $\mathrm{A}=5.82$ $v B=5.88, p<0.05$ ) and seasons (winter=5.89 v summer=5.82, $p<0.05$ ) as did the interactions between supermarket $x$ season $(p<0.05)$ and supermarket $x$ management $(p<0.05)$, although all differences were very small. While the $\mathrm{pH}$ was higher for winter than summer finished steaks in Supermarket $B$, no seasonal differences were detected from Supermarket $\mathrm{A}$. Also, while the $\mathrm{pH}$ was higher in organic compared to non-organic steaks in Supermarket $B$, there was no effect of management on $\mathrm{pH}$ in steaks from Supermarket A.

Steaks finished in winter were heavier $(p<0.01)$ than summer samples $(272 \vee 230 \mathrm{~g})$ with an interaction between supermarket $x$ management $(p<0.01)$, due to inconsistency in the weight of non-organic steaks between the 2 supermarkets. Non-organic steaks from supermarket A were heavier than those from supermarket B (275g v 224g) whereas organic steaks did not differ between supermarkets (252g). Colour was not influenced by the main factors $\left(I^{*}=37.6, a^{*}-24.4\right.$ and $\left.b^{*}=12.0\right)$ but for the chronometer value $a *$ for redness an interaction between management $x$ season was significant, $p<0.05)$. Whereas the a* value for non-organic beef was higher than that for organic beef in winter (25.9 $\vee 23.4$ ), there was no significant difference in summer (24.3). Thickness of steak (23 mm), cooking loss (23.9\%) and shear force $(28.3 \mathrm{~N})$ were not significantly affected the 3 experimental factors.

\subsection{Fatty acid composition}

While there was considerable variation in total FA content of muscle tissue (1180 to $7556 \mathrm{mg} / 100 \mathrm{~g}$ meat, with 5 of the 39 streaks exceeding $4000 \mathrm{mg} / 100 \mathrm{~g}$ meat) no significant effect of the 3 factors or their interactions were detected. On the other hand fat composition did vary with concentrations of individual and groups of FA in both IMF and SCF differing significantly between supermarkets, 
management and/or season, with many 2-way interactions. The wide range in total FA content had a major impact on the relationship between FA in IMF when expressed as (i) a proportion muscle tissue per se, or (ii) a proportion of total FA (TFA); differences proving significant for results expressed as the former did not necessarily correspond to those found to be significant for the latter. For this reason FA concentrations are presented both as a proportion of (a) muscle tissue (Table 1 shows data calculated as mg FA $100 \mathrm{~g} \mathrm{muscle}^{-1}$ ) and (b) TFA (Table 2 gives data calculated as g FA kg total FA ${ }^{-1}$ ). Table 3 shows corresponding values for SCF. Some 2-way interactions proved significant but there were no three-way interactions.

In some respects FA profiles in IMF and SCF show similarities since both were dominated by oleic (OA C18:1 c9, 37 \% TFA), palmitic (PA C16:0, $28 \%$ TFA), and to a lesser extent by stearic (SA C18:0, $13 \%$ TFA) acids, which together accounted for $78 \%$ of the total. The concentrations of these major fatty acids therefore correlate positively with TFA (as did C14:0 and MUFA), but for 16 individual FA, concentrations in IMF (relative to TFA) were negatively correlated ( ie a negative Pearson correlation coefficient) with total FA in IMF - their proportions diminished as total fat increased (results not shown). These were mainly, but not exclusively, unsaturated fatty acids and included LA and ALA (the main $n-6$ and $n-3$ found in meat), with total PUFA, total $n-6$ and $n-3$ LC all showing a strong negative correlation with total fat (Pearson's correlation<-0.7 and $p<0.001$ ). Hence at higher levels of IMF these form a lower proportion of the total FA.

Whilst IMF and SCF are both dominated by the same 3 major FA (OA, PA, and SA) the relative concentrations of OA, SA and many other individual and groups of FA in these 2 fat depots are inconsistent. There is poor correlation between levels in IMF and SCF (results not shown); for some (C14:0, C14:1 and C16:1) IMF concentrations are consistently lower than SCF (ratio < 1.0) whereas for LA, EPA, DPA, C20:3 n-6, C20:4 n-6, PUFA, n-6 and n-3LC, all steaks show preferential deposition in IMF compared to SCF (ratio>1.0). For many FA, variation in the IMF:SCF ratios were influenced by the experimental factors (Table 4), and for some individual and groups of FA this ratio was also significantly influenced by total fat content of the muscle tissue (Table 5). Two individual FA (C14:0, C17:0) and MUFA concentration showed a positive correlation with total fat content - hence at higher fat levels in the muscle, these increase more in IMF compared with SCF. On the other hand the negative correlations identified for many individual n-6 (LA, C18:2 c12c15, C20:3 and C20:4) and n-3 (ALA, and EPA), as well as various groups (PUFA, $n-6, n-3$ and $n-3$ LC) indicates that an increase in total muscle fat is associated with more of these FA appearing in SCF rather than muscle. 


\subsubsection{Effect of supermarket (Supermarket A vs. supermarket B)}

Differences in fat composition between steak purchased at the 2 retail outlets were fewer in number than those explained by other factors in this study. Significant differences were identified but restricted to minor fatty acids, not of recognised nutritional significance and only in 1 of the 3 sets of results; IMF relative to meat (table 1) or total fat (table 2) and SCF (table3). An exception to this statement applies to DHA (only found in IMF), results from supermarket A were $31 \%$ higher when expressed in muscle tissue and 40\% higher relative to total FA (table 1 and 2 respectively) than for supermarket B. Other differences in IMF include $12 \%$ less $\mathrm{C} 16: 1$ c9 but 33\% more C18:1 t6,7,8 in meat from Shop A than from shop B (table 2), although the latter was present at very low levels in all samples.

SCF was slightly more variable than IMF with differences identified for 7 individual FA and 1 calculated group (Table 3). SCF from Shop A was lower in short chain FA with $26 \%, 29 \%$ and $17 \%$ less C10, C12 and C14 respectively and it was also 51\% lower in DPA (giving $41 \%$ less $n-3$ LC) than SCF on steak from Supermarket B. In contrast SCF from supermarket A contained more C18:1 c12 (33\%), C18:2 t8c13 (12\%) and C20:4 n-6 (30\%) than fat from supermarket B steaks. All these differences are in mirror FA amounting in total to less than $50 \mathrm{~g} / \mathrm{kg}$ total fatty acid.

\subsubsection{Effect of management (Organic vs. non-organic)}

The production system indicated on packaging explained greater variation in meat fat composition than the supermarket of purchase; 22 of the 45 identified individual FA plus 6 of the 8 groups or calculated values, were significantly influenced by management. For 4 of these, variation was corroborated in all 3 data sets, whilst for 9 others they reached significance in 2 (Tables 1, 2 and 3). Organic meat contained more ALA than non-organic meat with concentrations $30 \%$ higher in IMF relative to meat (Table 1), 35\% in IMF relative to total FA (table 2 ) and $39 \%$ in SCF (Table 3 ), resulting in $24-31 \%$ more $n-3$ in organic meat (tables 1,2 and 3) and reducing the $n-6: n-3$ ratio by between 70 $87 \%$, in the various fractions. Organic meat contained only $29-33 \%$ of $\mathrm{C} 18: 1$ t10 found in nonorganic IMF and SCF. No C22:4 n-6 was found in SCF hence no difference identified between production systems although its concentrations were $57 \%$ and $60 \%$ higher in organic IMF relative to meat and total FA (respectively), in comparison to IMF from non-organic steaks.

Other differences in fat composition were identified, where their nature and magnitude were similar in all 3 data sets (Tables 1, 2 and 3) although only reached significance in 2. When comparing IMF relative to total FA (Table 2) and SCF (Table 3) organic meat contained more C15 (16 \& 23\%), C16:1 t9 (17 \& 20\%), vaccenic acid (VA C18:1 t11) (34 \& 44\%) and C18:2 t11c15 (38 \& 41\%) but less C18:1 c11 (9 \& 26\%) and C18:1 
c12 (57 \& 63\%). Organic steak also had more docosapentaenoic acid (DPA C22:5 n-3) (12 \& 32\%) and n-3 LC (17 \& 32\%), verified in IMF relative to muscle (Table 1 ) and SCF (Table 3 ) as well as $45 \& 50 \%$ more C20:3 n-3 in IMF relative to muscle (Table 1 ) and total fat (Table 2), respectively.

In addition to the influences described above covering more than 1 dataset, concentrations of a number of other nutritionally relevant FA did differ significantly with management. When IMF results were expressed relative to meat (Table 1), organic steak contained $24 \%$ more EPA but less LA $(14 \%)$ and $\gamma$-linolenic acid (25\%), hence was $15 \%$ lower in $n-6$ than non-organic meat. Results for IMF expressed as total FA (Table 2) shows 10\% more CLA in organic rather than non-organic meat. The SCF composition (Table 3) appears to be influenced by management to a greater extent than IMF with more individual FA showing significant differences in concentrations. Compared with nonorganic steak, organic meat SCF was $6 \%$ higher in SFA, driven by 14\% more SA, 18\% more C20:0 and $45 \%$ more C22:0 but was 9\% lower in OA resulting in 7\% lower MUFA content. Differences between production systems were also identified in at least 1 of the datasets for a number of minor FA not particularly relevant to our current knowledge of nutrition (Tables 1, 2 and 3).

\subsubsection{Effect of seasons (summer- finished vs. winter-finished)}

As with management, many FA concentrations differed between steak purchased in spring and those from autumn. A total of 24 individual FA and 5 calculated groups or ratios proved to be significantly affected by season of purchase (presumed to represent the finishing season) with differences for 3 FA consistent across all datasets and another 10 reaching significance in 2 sets, despite variation of similar magnitude in all 3 data sets (Tables 1,2 and 3$)$. Only those proving to be significant $(p<0.05)$ are mentioned.

Differences consistent across all results were for minor FA; C18: c9t13 and the non-specified FA were higher (62-120\% and 14-33\% respectively) and C18:1t9 was 21-44\% lower in steak bought in autumn compared with those bought in spring. DHA was found in IMF at over twice the concentrations in summer finished steak compared with winter finishing (irrespective of how results were expressed) although was absent from SCF. (Tables 1,2 and 3)

Comparing results for IMF relative to meat (table 1) and SCF (table 3) shows higher levels of DPA in IMF (18\%) and SCF (65\%) in summer compared with winter finishing, which (along with higher levels of DHA mentioned above) increases $n-3$ LC by $24 \%$ in IMF and $64 \%$ for SCF. Differences for other FA were significant in both IMF and SCF when the former is expressed relative to total FA, allowing for differences in fat content (comparing Tables 2 and 3). In these case, steak from summer finished animals was higher in C16:1 t9 (14 \& 33\%), C18:2 c9t12, t8 12 (44 \& 50\%), VA (55 \& 56\%) and CLA (78 
\& 61\%) but lower in OA (7 \& 8\%), C18:1 c15 (63 \& 73\%) and C20:0 (60 \& 33\%) compared with meat from spring purchase - the increases or decreases shown refer to IMF (Table 2) and SCF (Table 3) respectively. Long chain SFA were identified in low concentrations but both C22:0 and 23:0 showed seasonal variation. Concentrations of C23:0 in IMF were 60-62\% higher in summer than winter although was consistent in SCF over the seasons, however C22:0 results were atypical of any other FA. This differed significantly in all 3 data sets but, whereas IMF concentrations were 40 \& $50 \%$ lower in summer meat (relative to meat and TFA), it was found to be $69 \%$ higher in SCF from summer rather than winter samples - no other FA showed such divergence in accumulation between the fat depots.

As with differences explained by management, there were other FA showing seasonal variation in concentrations in only 1 set of results, many present at low levels, although potentially nutritionally relevant. Expressing IMF results relative to meat showed summer finished steak to be lower in C18:t12,13,14 (59\%) and C20:2 (63\%) but 24\% higher in C17:1 than winter meat. Converting IMF results relative to total FA showed summer meat to contain $25 \%$ more $n-3$ and double the levels of C18:1 c12 than winter meat but with 15\% less C17:0. Additional results for SCF show summer meat to have $14 \%$ more $\mathrm{C} 12: 0$ and $90 \%$ more $\mathrm{C} 20: 4 \mathrm{n}-6$ relative to steak from winter finishing but $19 \%$ less C18:2 c9,15.

\subsubsection{Interactions between supermarkets, management systems and seasons}

Eleven interactions were detected between main factors for FA results, all in minor FA, mostly of unknown nutritional relevance with the exception of a 2-way interaction between season $x$ supermarket for DHA in IMF. Irrespective of how this was expressed, autumn purchased steak from supermarket A contained substantially more DHA ( $3.9 \mathrm{mg} / 100 \mathrm{~g}$ beef or $1.5 \mathrm{~g} / \mathrm{kg}$ total FA) compared with those bought at this supermarket in spring $(1.1 \mathrm{mg} / 100 \mathrm{~g}$ beef or $0.4 \mathrm{~g} / \mathrm{kg}$ total FA), whereas DHA concentrations of steaks from supermarket $B$ did not change between summer and winter $(2.0 \mathrm{mg} / 100$ $\mathrm{g}$ beef or $0.7 \mathrm{~g} / \mathrm{kg}$ total FA and $1.6 \mathrm{mg} / 100 \mathrm{~g}$ beef or $0.6 \mathrm{~g} / \mathrm{kg}$ total FA respectively).Other interactions were identified between supermarket and management for C18:2 c12,15 in IMF as total FA, between supermarket and season for the unknown FA in SCF and between management and season for C18:2 t8c13 in SCF. Although found at very low levels, the long chain, odd numbered saturated acid C23:0 showed significant interactions between supermarket and season for IMF concentrations relative to meat and total FA as well as between management and season for its concentration in SCF.

\subsubsection{Comparing intramuscular and subcutaneous fat composition}

On the whole, most PUFA concentrations were consistently higher in IMF compared with SCF for every 
sample, although notable exceptions were CLA9 and a number of other C18:2 isomers (c9t13, c9t12/t9,12, t8c13 and t11c15), found at higher concentration in SCF than IMF for most but not all samples (table 4). Among MUFA the situation was variable with some being more abundant in SCF (including VA, other C18: isomers and C20:1) while others in higher concentrations in IMF( including C18:1 c11 and C18:1 t9). Whereas most SFA were more abundant in SCF compared with IMF, a notable exception was $\mathrm{C} 18: 0$ and minor FA C10:0, C22:0 and C23:0.

There were examples where the concentration ratios between IMF and SCF were influenced by the study factors (Table 4). Generally OA was equally distributed between the 2 depots with an average ratio of 1.01 for all samples; however, this shifted to 1.04 for organic samples, with slightly greater deposition in IMF (compared with SCF), which differed $(\mathrm{p}<0.05)$ from the non-organic samples which had consistent deposition at 0.99 . A very similar pattern was found for $\mathrm{C} 18: 1 \mathrm{c} 9$, and in this case there was also a shift from uniform deposition in winter to greater accumulation in IMF in summer (ratio $0.98 \vee 1.20, p<0.001)$. This season change was more pronounced for $\mathrm{C} 18: 1 \mathrm{c} 12$ which was higher in SCF, rather than IMF in winter steak but reversed for meat bought in the autumn (ratio $1.18 \mathrm{v} 0.68$ $\mathrm{p}<0.01)$ and also for $\mathrm{C22:0}$ which changed in the opposite direction - a ratio of 0.61 in winter and 1.65 in summer $(p<0.001)$ shows preferential deposition into IMF in winter but SCF in summer. Management system also influenced C20:0 depositions, with organic steaks having more in SCF but non-organic steak had higher concentrations in IMF (ratios 0.88 v 1.36, $p<0.05$ ). Other examples where this ratio appeared to be changed by study factors (Table 4) are less extreme, showing even greater accumulation in IMF or SCF rather than a change in emphasis from 1 depot to the other.

\subsection{Fatty acid intakes}

Simulated fatty acid intakes and contribution towards dietary recommended are given in Table 6, disregarding differences between supermarkets and presenting mean FA profiles of organic and nonorganic steaks in different seasons. The supply of many nutritionally relevant unsaturated FA in summer organic steaks is significantly greater than from non-organic winter finished steaks with the other 2 steaks being intermediate and not differing statistically from other categories. This applied to; VA, CLA9, ALA, EPA, docosapentaenoic acid (C22:5 n-3, DPA), PUFA, n-3 and n-3 LC, whereas DHA supply was higher from summer meat (regardless of production system) and differences between the production systems did not differ significantly within each season. The ratio of $n-6: n-3$ estimated to be consumed was lower from organic steak in both seasons, compared to non-organic winter meat. 


\section{Discussion}

\subsection{Samples and Production Background}

Beef quality is confounded by multiple factors such as breed, sex, age, diet, slaughter condition and post-slaughter treatment (Raes, et al., 2004; Razminowicz, et al., 2006; N. Scollan, et al., 2006). Although individual factors have been the focus of previous studies, in commercial practice the overall quality is determined by complex interactions between these. This study focused on beef at retail outlets with most of these factors unknown, except for (a) the likely season of finishing and (b) whether or not cattle were managed to organic standards. Although the number of samples is rather limited $(n=39$ ), the total organic market shares of the supermarket A and B in the UK is about $46 \%$ (Soil Association, 2012), thus steaks in this research are thought to be reasonably representative of organic beef available for consumers during the sampling period.

Despite retailers production guidelines there is likely to be greater variation in retail samples compared to those from controlled experimental conditions. The provenance of a particular steak might be very different to that of adjacent packs sold under the same brand; they could come from different breed, sex and/or age of animals reared on different farms with different feeds. Nevertheless, such deviation exists in contemporary food supply chains so, while explaining the level of variation, the data presented provide a valuable first estimate of the magnitude of quality/composition differences in beef from different supermarket chains, management systems and finishing seasons.

\subsection{Meat quality (weight, $\mathrm{pH}$, colour and shear force)}

Meat was purchased randomly yet summer steaks were significantly lighter than winter samples and an interaction between season and management was observed. Since thickness of steaks did not differ, the discrepancy in weight could be explained by muscle areas, which could arise with differences in carcase weight or cut position (posterior or anterior part of the ML muscle). The observed $\mathrm{pH}$ range 5.6-6.1 is comparable with past studies of ML (Page, Wulf, \& Schwotzer, 2001; Purchas, 1990; Razminowicz, et al., 2006) at the higher end of the range; possibly explained by frozen storage (2-3 month), which can raise the pH of meat (Penney, Bell, \& Moorhead, 1998). The WBSF in this study $(18.8 \mathrm{~N}$ and $37.1 \mathrm{~N})$ corresponds to the lower end of values reported on $\mathrm{ML}$ from various breeds or ages; 26.8-40.3 N (Raes, et al., 2003), 31.4-39.4 N (French, et al., 2000), 34.3-39.2 N (Cho, et al., 2006), 34.3 N and 36.0 N (May, Sturdivant, Lunt, Miller, \& Smith, 1993) and 34.7-52.5 N (Razminowicz, et al., 2006). Although cooking method differed between studies (in temperature and whether grilled or boiled) all steaks in this study possessed adequate tenderness, despite the rather long frozen storage that could influence results. Our beef may have been aged longer than other studies; whereas 
experimental aging of beef is often $\leq 14$ days (Cho, et al., 2006; French, et al., 2000), one of the brands used in this study stated 28 days.

\subsection{Analytical and computation methods}

Synthesising FAME directly from wet samples without lipid extraction does not quantify fat content although the sum of individual FA in muscle tissue can be used as a reasonable estimate since fatty acids content of lean beef is proportional (91\%) to total fat content (Food and Agriculture Organization of the United Nations, 2003). Total FA content of IMF did vary considerably in this study, as much within as between categories of steaks and resulted in the lack of identifiable difference between supermarkets, management system or season. This variation implies a lack of consistency within each 'brand' for breeding, feeding and husbandry regimes- or even within products that claim to be of 'grassor forage-based products' in the UK.

Although many papers on meat fat present FA concentrations relative to muscle tissue, the unexplained variation in total fatty acid content of IMF in this study warranted expressing results relative to total $F A$, to give a better indication of nutritional consequences which relate to fat composition as much as quantity (Food and Agriculture Organisation of the United Nations, 2010). Having IMF and SCF fat profiles in the same units also allowed comparison of relative accumulation of individual FA in these depots and gives an insight into potential health benefits from removal (or consumption) of SCF. Fatty acids showing IMF:SCF concentration ratios of less than 1 indicate preferential deposition in SCF (which can be removed and avoided by consumers) whereas values over 1 suggest greater accumulation in muscle, making consumption unavoidable. By considering the impact of retail source, production management and/or season on these values we get an insight into relative changes in fat deposition patterns and hence nutritional quality of the meat (with or without visible fat consumption).

\subsection{Fat content and composition}

On the whole, total fat in IMF in this study was lower than reported for 'Beef, sirloin steak, raw, lean' in accepted food composition tables (Food Standards Agency, 2002) (3.1 vs $4.5 \mathrm{~g}$ fat/100 g beef). Whereas concentrations of dominant FA (PA, OA and SA) were similar to published values, proportions of short chain FA (C10, C12 and C15) were also slightly lower in this study but the most striking discrepancies with composition table data was found for FA with 20+ carbon chains - results in this study were 3-4 fold higher than published values. Variation in meat fat profiles is known to exists (Wood, et al., 2008) making the existence of 'standard' or average composition questionable. At 3.1 \% our mean TFA content of IMF (equivalent to $3.4 \%$ total fat) is at the lower end of the 3-4 \% fat 
acceptable for consumer satisfaction (Hocquette, et al., 2010) with 22 of the 39 steaks failing to meet this threshold. This low level of IMF might be a consequence of the lack of standards to quantify or reward marbling in UK beef (although it is interesting to note that this it did not appear to have a negative impact on sheer force measured in this study).

The review by Wood, et al., (2008) on fat deposition and composition differentiates phospholipids (structural FA found in cellular membrane and more abundant in IMF) and neutral triglycerides, the primary role of which is energy storage. Although this study did not make this distinction, our findings of strong negative correlations between many individual PUFA within IMF (and their various groupings) with total fat supports the theory of dilution of structural [phospho] lipids in muscle with increasing fat stored for energy. This is reinforced by the positive relationship as PA and OA concentrations in IMF increase in line with TFA. Results for fat profiles are discussed across 3 data sets considering FA concentrations in a) IMF expresses relative to muscle - Table 1, b) IMF relative to total fat- Table 2 and c) SCF - Table 3. One striking feature is the divergence between these 3 sets of results - for many of the 'significant differences'; the apparent impact of 'supermarket', 'management' and 'season' is not always consistent. However, for some parameters a consistent pattern was found in all 3 datasets.

\subsubsection{Supermarket}

Not surprisingly, the shop where steak was purchased appeared to have the less influence over fat composition than other factors, possibly implying a less meaningful impact. None of the individual or groups of FA showed a significant influence in all 3 sets of results and the only FA of recognised nutritional relevance altered in 2 of the 3 was DHA concentrations. IMF from supermarket A contained more DHA than Supermarket B (in both muscle and TFA), mainly due to the higher DHA content of summer samples. This was rather unexpected since differences for other $n-3$ (ALA, C20:3 n-3, EPA, DPA) in IMF or SCF were not significant and concentrations for supermarket A were numerically lower. Warren, et al., (2008) report greater apparent conversion of ALA to DHA in Holstein-Friesian compared with Angus-cross cattle and it could be that Supermarket A were sourcing a different breed of cattle than Supermarket B, when beef was purchased in late summer. The supermarket influenced FA concentrations in SCF more than IMF composition, although, differences were largely in minor FA of unknown nutritional relevance with the exception of slightly less C14:0 (a potent promoter of high risk low density lipoprotein cholesterol - (Food and Agriculture Organisation of the United Nations, 2010)) and higher n-3 LC (a good thing - (Ruxton, et al., 2007)) in SCF from Supermarket A. However, overall differences were minor and unlikely to be of nutritional relevance. 


\subsubsection{Management}

The designation of organic had greater impact than the supermarket of purchase on nutritionally relevant FA with $\mathrm{C} 18: 1$ t10, ALA $n-3$, and the ratio of n6:n3 showing consistent differences in all 3 sets of results. High levels of concentrate feeding to ruminants are known to favour C18:t10 accumulation in the rumen (especially if acidosis occurs; (Kramer, et al., 2004)) and can lead to its incorporation into milk and meat fat (Daley, et al., 2010). This could explain concentrations in organic steak being approximately one third those for non-organic meat, implying the latter came from cattle receiving concentrated diets with less forage. Several studies report more n-3 and CLA in organic compared to conventional milk and dairy products and this is thought to be mainly due to a higher ALA intakes from (a) a greater proportion of forage, fresh or ensiled, in the diet and (b) partial replacement of grasses by legumes such as clover (Daley, et al., 2010; Steinshamn \& Thuen, 2008). This study corroborates this effect; the total n-3 content of organic meat was 31-44 \% higher than that of non-organic beef and resulted in a consistently lower ratio of $n 6: n 3$. This is recognised to balance the dominance of $n-6$ in typical western diets (Simopoulos, 2002), often from vegetable oils, and has been described as nutritionally desirable. Although not always statistically significant, individual n-3 (ALA, C20:3 n-3, EPA, DPA and), VA and CLA9 were also found in higher concentrations in organic meat. VA is an intermediate product of rumen bio-hydrogenation and acts as a precursor for the influential CLA9 - in both livestock and human metabolism (Palmquist, Lock, Shingfield, \& Bauman, 2005). Like ALA and other n-3, VA appearance in ruminant products tends to indicate livestock with a high reliance on forage based diets, especially from pasture grazing (Butler, et al., 2008; Daley, et al., 2010) and is usually highly correlated to CLA9 concentrations. In this study differences between organic and non-organic IMF for CLA9 were proportionally comparable to VA but only reached statistical significance when expressed relative to total fat.

The negative relationship between some unsaturated fatty acids and total fat in IMF could contribute to the explanation of differences between organic and non-organic beef. Although not significant, the latter was approximately $10 \%$ higher in fat - so might be expected to have less unsaturated fatty acids. This theory however does not support higher concentration of LA and n-6 found in IMF of non-organic steaks (both with a strong negative correlation with total FA), implying composition differences were at least partly a direct consequence of the rearing system, diets and FA supply discussed above.

\subsubsection{Season}

Aspects of beef quality have been reviewed by Daley, et.al., (2010) who report contrasting FA profiles between grass and grain fed cattle. This might be expected to lead to seasonal changes in fat 
composition of cattle that graze in summer and consume conserved silage and concentrated feeds in winter -as in UK. Seasonal differences in the fat composition of ruminant products are well recognised due to cyclical patterns in herbage growth and hence animal nutrition (Butler, et al., 2008; Pestana, et al., 2012); however, in this study many expected differences were not significant in all 3 data sets, possibly implying some concentrated feeds and/or conserved forage being fed in summer. Generally there was good agreement in seasonal differences identified as significant for SCF and IMF when expressed relative to TFA but these did not always correspond to those identified in IMF as a proportion of muscle tissue. This was the case with VA and CLA9; both contributing substantially more to of TFA in IMF and SCF for meat bought in autumn (after summer finishing), although differences in IMF relative to muscle tissue were less marked and non-significant. Elevated VA and CLA content suggests seasonal cattle feeding patterns with greater reliance on fresh herbage in summer (Daley, et al., 2010), but compared with the impact of management, there was a less pronounced effect of season on individual and total n-3 concentrations, with significant differences only detected for DPA, DHA and hence LC n-3 in IMF. A similar trend has been reported for dairy products where both management (organic vs conventional) and season influence milk concentrations of VA, CLA and n-3. However, organic management was found to be a stronger driver for $n-3$ concentrations (thought to be due to the inclusion of legumes in pastures and silage) whereas season was a greater driver for VA and CLA concentrations in milk (Butler, et al., 2011).

As with the systems' comparison, lower levels of unsaturated fats in winter finished beef could be partially explained by its higher TFA content in IMF. However, again this theory is challenged by tendency for greater LA appearance and numerically higher $n-6$ levels in winter finished steaks, despite the fact this unsaturated fatty acids shows a strong negative correlation with TFA. In both 'system' and 'season' comparisons, this suggests differences in FA profiles are more likely to reflect dietary FA supply, rather than an indirect effect that diet may has on fat deposition within the carcases.

\section{5. . Comparing intramuscular and subcutaneous fat composition}

In view of the structural role of many PUFA within phospholipids, discrepancies between IMF and SCF composition are perhaps not surprising, especially given the relatively low levels of 'marbling' detected in this study. The review of Wood, et al., (2008) identified CLA as a PUFA defying this general trend by being deposited more in the SCF rather than IMF, most likely from $\Delta 9$-desaturase activity on VA in adipose tissue. Results here concur; whereas most PUFA were consistently higher in IMF than SCF in every sample, a notable exception was CLA9 which showed higher accumulation in SCF. This also applies to a number of other C18:2 isomers (both cis and trans forms with double bonds between carbon number 8 and 13), suggesting they too may be formed in adipose tissue rather than as 
functional phospholipids.

Other noticeable exception to the general trend of PUFA levels being higher in IMF and SFA accumulating in SCF are C18:0, C22:0 and C23:0, all of which appeared at higher concentrations in IMF rather than SCF. A possible explanation for lower levels of stearic acid in SCF could be its conversion to $\mathrm{OA}$ by the $\Delta 9$-desaturase enzyme, known to be active in adipose tissue (Yang, Larsen, Smith, \& Tume, 1999), although there is no clear explanation for the appearance of the longer chain saturated fatty acids in adipose tissue, all be it at very low concentrations.

\subsection{Implications for human nutrition.}

Calculated intakes of many nutritionally beneficial FA differ considerably, with summer organic steak supplying significantly more ALA, CLA, VA, EPA, DPA, DHA, PUFA, n-3 and n-3 LC than winter nonorganic steak. Recognised guidelines for fat and fatty acid intakes vary between countries and are often expressed relative to energy intake rather than absolute daily intakes making it difficult to assess to what extent these steaks contribute to a healthy diet. This is especially true for CLA which, although widely recognised as potentially beneficial, has no recommendations for intake. On the other hand guidelines other FA intakes are specified, Food and Agriculture Organisation of the United Nations (2010) suggests adult target SFA consumption at less than $10 \%$ of calorie intake, ALA at least $0.2 \%$ and longer chain n-3 for adults at a minimum of $250 \mathrm{mg} /$ day. As discussed, season of purchase is less influential on $n-3$ content of meat than the management system and our simulation suggests FA supply from a single organic steak (averaged over both seasons) are more aligned with these daily recommendations by supplying $36 \%$ of SFA, $35 \%$ of ALA and $34 \%$ n-3-LC targets compared to $35 \%$ SFA but only $25 \%$ ALA and $27 \%$ n-LC from the non-organic steak. These results support other claims that, with concerns over the sustainability of increasing fish consumption (2012), lean red meat from high forage systems relying on clover, can make a valuable contribution to population $n-3$ consumption - without necessarily increasing risks associated with excessive SFA intake, especially if SCF is avoided. Interestingly, measured benefits in consumer plasma and platelet n-3 LC content described by McAfee, et al., (2011) resulted from consumption of beef from grass fed cattle with lower levels of $n-3$ and $n-3$ LC than recorded for organic meat in this study.

Another thought-provoking finding is, because CLA and VA tend to be deposited in SCF rather than IMF this simulation shows consumption of only $10 \mathrm{~g}$ of fatty acids in SCF (approximately $4 \%$ of the steak by weight) provides $74-77 \%$ of total CLA and $65-70 \%$ of VA - indicating the relative importance of SCF in this respect. 


\section{Conclusion}

This study demonstrates considerable differences in beef FA profiles (within muscle and in visible fat) between seasons or indicated production systems - despite claims that all steak originated from cattle fed grass or forage. Although there is no labelling guideline or industry-wide standards for "foragerich" or "grass-based" production systems, such terms could potentially be misleading for consumers who expect meat quality consistent with all forage- or grass-fed beef. Organic, summer-finished beef would provide nutritionally more favourable FA profiles with higher n-3 (ALA, EPA, DPA and DHA), CLA and VA compared to non-organic, winter finished samples. Nevertheless, it would be presumptuous to generalise trait of UK beef production over a range of production systems and seasons, by the result of this relatively small study in a single year. A comparable study looking at milk quality but carried out over 2 years (Butler, et al., 2011) showed differences in FA profiles between years with contrasting weather conditions (in addition to season, 'brand' and management systems) which would have a bearing on summer and winter feeding and hence FA profiles in livestock products. The number of samples in this study might be considered relatively low, hence lacking in the level of sensitivity to detect relatively small differences, but even on this dataset, many significant differences could be detected for nutritionally relevant compounds. A larger study possibly encompassing a wider range of production systems with greater insight into their features (breeding and feeding policy on the farms) could identify and explain variation in the fatty acid profiles between supermarkets, production systems and finishing season.

\section{Acknowledgements:}

One of us (SK) was in receipt of funding from the National Personnel Authority and Ministry of Agriculture, Forestry and Fisheries of Japan in the framework of the Japanese Government Long-Term Fellowship Program.

\section{References:}

Alfaia, C. M. M., Quaresma, M. A. G., Castro, M. L. F., Martins, S. I. V., Portugal, A. P. V., Fontes, C. M. G. A., Bessa, R. J. B., \& Prates, J. A. M. (2006). Fatty acid composition, including isomeric profile of conjugated linoleic acid, and cholesterol in Mertolenga-PDO beef. Journal of the Science of Food and Agriculture, 86(13), 2196-2205.

Alfaia, C. M. M., Ribeiro, V. S. S., Lourenço, M. R. A., Quaresma, M. A. G., Martins, S. I. V., Portugal, A. P. V., Fontes, C. M. G. A., Bessa, R. J. B., Castro, M. L. F., \& Prates, J. A. M. (2006). Fatty acid composition, conjugated linoleic acid isomers and cholesterol in beef from crossbred bullocks intensively produced and from Alentejana purebred bullocks reared according to Carnalentejana-PDO specifications. Meat Science, 72(3), 425-436.

Angood, K. M., Wood, J. D., Nute, G. R., Whittington, F. M., Hughes, S. I., \& Sheard, P. R. (2008). A compa rison of organic and conventionally-produced lamb purchased from three major UK supermarkets: Price, eating quality and fatty acid composition. Meat Science, 78(3), 176-184.

Bhattacharya, A., Banu, J., Rahman, M., Causey, J., \& Fernandes, G. (2006). Biological effects of conjugated linoleic acids in health and disease. Journal of Nutritional Biochemistry, 17(12), 789-810. 
Butler, G., Nielsen, J. H., Slots, T., Seal, C., Eyre, M. D., Sanderson, R., \& Leifert, C. (2008). Fatty acid and fat-soluble antioxidant concentrations in milk from high- and low-input conventional and organic systems: Seasonal variation. Journal of the Science of Food and Agriculture, 88(8), 1431-1441.

Butler, G., Stergiadis, S., Seal, C., Eyre, M., \& Leifert, C. (2011). Fat composition of organic and conventional retail milk in northeast England. Journal of Dairy Science, 94(1), 24-36.

Calder, P. C. (2004). n-3 Fatty acids and cardiovascular disease: Evidence explained and mechanisms explored. Clinical Science, 107(1), 1-11.

Cho, Y. M., Choi, H., Hwang, I. H., Kim, Y. K., \& Myung, K. H. (2006). Effects of 25-hydroxyvitamin D3 and manipulated dietary cation-anion difference on the tenderness of beef from cull native Korean cows. Journal of Animal Science, 84(6), 1481-1488.

Committee on Medical Aspects of Food Policy. (1984). Diet and Cardiovascular Disease. In Report on Health and Social Subjects (Vol. 28). London, UK.

Crawley, M. J. (2007). The R book. Chichester: John Wiley \& Sons.

Daley, C. A., Abbott, A., Doyle, P. S., Nader, G. A., \& Larson, S. (2010). A review of fatty acid profiles and antioxidant content in grass-fed and grain-fed beef. Nutrition Journal, $9(1)$.

Ellis, K. A., Innocent, G., Grove-White, D., Cripps, P., McLean, W. G., Howard, C. V., \& Mihm, M. (2006). Comparing the Fatty Acid Composition of Organic and Conventional Milk. Journal of Dairy Science, 89(6), 1938-1950.

European Commission. (2008). Commission Regulation (EC) No 889/2008 of 5 September 2008 laying down detailed rules for the implementation of Council Regulation (EC) No 834/2007 on organic production and labelling of organic products with regard to organic production, labelling and control. In.

European Food Safety Authority. (2010). Scientific Opinion on Dietary Reference Values for fats, including saturated fatty acids, polyunsaturated fatty acids, monounsaturated fatty acids, trans fatty acids, and cholesterol. EFSA journal, $8(3)$.

Food and Agriculture Organisation of the United Nations. (2010). Fats and fatty acids in human nutrition. Report of an expert consultation. In FAO Food and Nutrition (Vol. 91). Rome: Food and Agriculture Organisation of United Nations.

Food and Agriculture Organization of the United Nations. (2003). Conventions and modes of expression of food composition data. In H. Greenfield \& D. Southgate (Eds.), Food and composition data - Production, management and use (pp. 170). Rome.

Food and Agriculture Organization of the United Nations: Fisheries and Aquaculture Department. (2012). The state of world fisheries and aquaculture. In Food and Agriculture Organization of the United Nations (Ed.), (Vol. 2012). Rome.

Food Standards Agency. (2002). McCance and Widdowson's the composition of foods. Cambridge: Royal Society of Chemistry.

Fredriksson Eriksson, S., \& Pickova, J. (2007). Fatty acids and tocopherol levels in M. Longissimus dorsi of beef cattle in Sweden - A comparison between seasonal diets. Meat Science, 76(4), 746-754.

French, P., O'Riordan, E. G., Monahan, F. J., Caffrey, P. J., Vidal, M., Mooney, M. T., Troy, D. J., \& Moloney, A. P. (2000). Meat quality of steers finished on autumn grass, grass silage or concentrate-based diets. Meat Science, 56(2), 173180.

Hocquette, J. F., Gondret, F., Baza, E., Mdale, F., Jurie, C., \& Pethick, D. W. (2010). Intramuscular fat content in meatproducing animals: Development, genetic and nutritional control, and identification of putative markers. Animal, 4(2), 303-319.

Howe, P., Meyer, B., Record, S., \& Baghurst, K. (2006). Dietary intake of long-chain $\omega-3$ polyunsaturated fatty acids: contribution of meat sources. Nutrition, 22(1), 47-53.

Jones, S. J., Guru, A., Singh, V., Carpenter, B., Calkins, C. R., \& Johnson, D. (2004). Bovine Myology and Muscle Profiling. In.

Kraft, J., Kramer, J. K. G., Schoene, F., Chambers, J. R., \& Jahreis, G. (2008). Extensive Analysis of Long-Chain Polyunsaturated Fatty Acids, CLA, trans-18:1 Isomers, and Plasmalogenic Lipids in Different Retail Beef types. Journal of Agricultural and Food Chemistry, 56(12), 4775-4782.

Kramer, J. K. G., Cruz-Hernandez, C., Deng, Z., Zhou, J., Jahreis, G., \& Dugan, M. E. R. (2004). Analysis of conjugated linoleic acid and trans 18:1 isomers in synthetic and animal products. The American Journal of Clinical Nutrition, 79(6), 1137S-1145S. 
May, S. G., Sturdivant, C. A., Lunt, D. K., Miller, R. K., \& Smith, S. B. (1993). Comparison of sensory characteristics and fatty acid composition between Wagyu crossbred and Angus steers. Meat Science, 35(3), 289-298.

McAfee, A. J., McSorley, E. M., Cuskelly, G. J., Fearon, A. M., Moss, B. W., Beattie, J. A. M., Wallace, J. M. W., Bonham, M. P., \& Strain, J. J. (2011). Red meat from animals offered a grass diet increases plasma and platelet $n-3$ PUFA in healthy consumers. British Journal of Nutrition, 105(1), 80-89.

McAfee, A. J., McSorley, E. M., Cuskelly, G. J., Moss, B. W., Wallace, J. M. W., Bonham, M. P., \& Fearon, A. M. (2010). Red meat consumption: An overview of the risks and benefits. Meat Science, 84(1), 1-13.

Meyer, B., Mann, N., Lewis, J., Milligan, G., Sinclair, A., \& Howe, P. (2003). Dietary intakes and food sources of omega-6 and omega-3 polyunsaturated fatty acids. Lipids, 38(4), 391-398.

Ngeh-Ngwainbi, J., Lin, J., \& Chandler, A. (1997). Determination of total, saturated, unsaturated, and monounsaturated fats in cereal products by acid hydrolysis and capillary gas chromatography: collaborative study. Journal of AOAC International, 80(2), 359-372.

O'Fallon, J. V., Busboom, J. R., Nelson, M. L., \& Gaskins, C. T. (2007). A direct method for fatty acid methyl ester synthesis: Application to wet meat tissues, oils, and feedstuffs. Journal of Animal Science, 85(6), 1511-1521.

Page, J. K., Wulf, D. M., \& Schwotzer, T. R. (2001). A survey of beef muscle color and pH. Journal of Animal Science, 79(3), 678-687.

Palmquist, D. L., Lock, A. L., Shingfield, K. J., \& Bauman, D. E. (2005). Biosynthesis of Conjugated Linoleic Acid in Ruminants and Humans. In (Vol. 50, pp. 179-217).

Penney, N., Bell, R. G., \& Moorhead, S. M. (1998). Performance during retail display of hot and cold boned beef striploins after chilled storage in vacuum or carbon dioxide packaging. Food Research International, 31(6-7), 521-527.

Pestana, J. M., Costa, A. S., Martins, S. V., Alfaia, C. M., Alves, S. P., Lopes, P. A., Bessa, R. J., \& Prates, J. A. (2012). Effect of slaughter season and muscle type on the fatty acid composition, including conjugated linoleic acid isomers, and nutritional value of intramuscular fat in organic beef. Journal of the Science of Food and Agriculture.

Purchas, R. W. (1990). An assessment of the role of pH differences in determining the relative tenderness of meat from bulls and steers. Meat Science, 27(2), 129-140.

R Development Core Team. (2009). R: a language and environment for statistical computing. In (Vol. Version 2.11.1 (201005-31)). Vienna: R Foundation for Statistical Computing, Vienna, Austria

Raes, K., Balcaen, A., Dirinck, P., De Winne, A., Claeys, E., Demeyer, D., \& De Smet, S. (2003). Meat quality, fatty acid composition and flavour analysis in Belgian retail beef. Meat Science, 65(4), 1237-1246.

Raes, K., De Smet, S., \& Demeyer, D. (2004). Effect of dietary fatty acids on incorporation of long chain polyunsaturated fatty acids and conjugated linoleic acid in lamb, beef and pork meat: a review. Animal Feed Science and Technology, 113(1-4), 199-221.

Razminowicz, R. H., Kreuzer, M., \& Scheeder, M. R. L. (2006). Quality of retail beef from two grass-based production systems in comparison with conventional beef. Meat Science, 73(2), 351-361.

Ruxton, C. H. S., Reed, S. C., Simpson, J. A., \& Millington, K. J. (2007). The health benefits of omega-3 polyunsaturated fatty acids: A review of the evidence. Journal of Human Nutrition and Dietetics, 20(3), 275-285.

Scollan, N., Hocquette, J. F., Nuernberg, K., Dannenberger, D., Richardson, I., \& Moloney, A. (2006). Innovations in beef production systems that enhance the nutritional and health value of beef lipids and their relationship with meat quality. Meat Science, 74(1), 17-33.

Scollan, N. D., Kim, E.J., Lee, M.R.F., Whittington, F., and Richardson, R.I. . (2008). Environmental Impacts on the n-3 Content of Food from Ruminant Animals. In Health Benefits of Organic Food: Effects of the Environment (pp. 50-69).

Simopoulos, A. P. (2002). The importance of the ratio of omega-6/omega-3 essential fatty acids. Biomedicine and Pharmacotherapy, 56(8), 365-379.

Soil Association. (2012). Organic market report 2012. In.

Steinshamn, H., \& Thuen, E. (2008). White or red clover-grass silage in organic dairy milk production: Grassland productivity and milk production responses with different levels of concentrate. Livestock Science, 119(1-3), 202-215.

UK Department of Health. (2008). Headline results from years 1, 2 and 3 (combined) of the rolling programme (2008/2009 - 2010/2011). In B. Bates, A. Lennox, A. Prentice, C. Bates \& G. Swan (Eds.), The National Diet and Nutrition Survey. 
Warren, H. E., Scollan, N. D., Enser, M., Hughes, S. I., Richardson, R. I., \& Wood, J. D. (2008). Effects of breed and a concentrate or grass silage diet on beef quality in cattle of 3 ages. I: Animal performance, carcass quality and muscle fatty acid composition. Meat Science, 78(3), 256-269.

Williams, C. M., \& Burdge, G. (2006). Long-chain n-3 PUFA: plant v. marine sources. Proceedings of the Nutrition Society, 65(01), 42-50.

Wood, J. D., Enser, M., Fisher, A. V., Nute, G. R., Sheard, P. R., Richardson, R. I., Hughes, S. I., \& Whittington, F. M. (2008). Fat deposition, fatty acid composition and meat quality: A review. Meat Science, 78(4), 343-358.

Yang, A., Larsen, T., Smith, S., \& Tume, R. (1999). $\Delta 9$ desaturase activity in bovine subcutaneous adipose tissue of different fatty acid compositiondesaturase activity in bovine subcutaneous adipose tissue of different fatty acid composition. Lipids, 34(9), 971-978. 
Table 1. Fatty acid concentrations (mg/100g muscle) in intramuscular fat of sirloin steaks (mean values for main factors, composite standard errors of means (sem) and ANOVA P-values for main factors and interactions)

\begin{tabular}{|c|c|c|c|c|c|c|c|c|c|c|c|c|c|}
\hline \multirow[b]{3}{*}{ Fatty acid } & \multicolumn{2}{|c|}{ Supermarket } & \multicolumn{2}{|c|}{ Management $^{\mathrm{a}}$} & \multicolumn{2}{|c|}{ Season $^{b}$} & \multirow[b]{3}{*}{ sem } & \multicolumn{6}{|c|}{$p^{-V^{2}}$} \\
\hline & \multirow{2}{*}{$\begin{array}{c}A \\
(n=19)\end{array}$} & \multirow{2}{*}{$\begin{array}{c}B \\
(n=20)\end{array}$} & \multirow{2}{*}{$\begin{array}{c}\text { Org } \\
(n=20)\end{array}$} & \multirow{2}{*}{$\begin{array}{l}\text { No-org } \\
(n=19)\end{array}$} & \multirow{2}{*}{$\begin{array}{l}\text { Win } \\
(n=19)\end{array}$} & \multirow{2}{*}{$\begin{array}{l}\text { Sum } \\
(n=20)\end{array}$} & & \multicolumn{3}{|c|}{ Main factors ${ }^{c}$} & \multicolumn{3}{|c|}{ Interactions } \\
\hline & & & & & & & & Su & M & Se & SuxM & $\begin{array}{c}\text { SuxS } \\
\mathrm{e}\end{array}$ & MxSe \\
\hline C10:0 & 1.1 & 1.5 & 1.2 & 1.3 & 1.3 & 1.3 & 0.13 & ns & ns & ns & ns & ns & ns \\
\hline C12:0 & 1.4 & 1.9 & 1.6 & 1.8 & 1.7 & 1.7 & 0.16 & ns & ns & ns & ns & ns & ns \\
\hline C14.0 & 73.4 & 94.5 & 80.4 & 88.3 & 91.7 & 77.1 & 7.50 & ns & ns & ns & ns & ns & ns \\
\hline C14:1 & 17.2 & 23.1 & 17.8 & 22.8 & 22.1 & 18.5 & 2.22 & ns & ns & ns & ns & ns & ns \\
\hline C15:0 & 12.1 & 13.4 & 13.1 & 12.4 & 14.0 & 11.6 & 1.03 & ns & ns & ns & ns & ns & ns \\
\hline C16:0 & 802 & 930 & 829 & 908 & 913 & 824 & 67.6 & ns & ns & ns & ns & ns & ns \\
\hline c9 C16:1 & 110 & 141 & 118 & 134 & 133 & 119 & 11.2 & ns & ns & ns & ns & ns & ns \\
\hline t9 C16:1 & 11.8 & 13.9 & 13.5 & 12.3 & 12.0 & 13.7 & 0.87 & ns & ns & ns & ns & ns & ns \\
\hline C17:0 & 27.5 & 28.8 & 27.4 & 29.0 & 32.5 & 24.1 & 2.47 & ns & ns & ns & ns & ns & ns \\
\hline C17:1 & 2.5 & 2.3 & 2.3 & 2.4 & 2.1 & 2.6 & 0.11 & ns & ns & $*$ & ns & ns & $\mathrm{t}$ \\
\hline C18:0 & 434 & 461 & 439 & 457 & 457 & 439 & 30.1 & ns & ns & ns & ns & ns & ns \\
\hline C18:1 & & & & & & & & & & & & & \\
\hline$c 9(O A)^{e}$ & 1130 & 1242 & 1111 & 1267 & 1304 & 1076 & 95.5 & ns & ns & ns & ns & ns & ns \\
\hline c11 & 53.6 & 60.9 & 52.1 & 62.8 & 55.9 & 58.7 & 4.49 & ns & ns & ns & ns & ns & ns \\
\hline c12 & 2.8 & 2.8 & 2.1 & 3.5 & 1.9 & 3.7 & 0.38 & ns & ns & ns & ns & ns & ns \\
\hline c13 & 6.1 & 7.2 & 5.2 & 8.2 & 7.4 & 6.0 & 0.86 & ns & $\mathrm{t}$ & ns & ns & ns & ns \\
\hline $\mathrm{c} 14+\mathrm{t} 16$ & 4.5 & 4.9 & 4.8 & 4.6 & 5.1 & 4.3 & 0.41 & ns & ns & ns & ns & ns & ns \\
\hline c15 & 1.9 & 2.4 & 2.0 & 2.3 & 2.9 & 1.5 & 0.26 & ns & ns & ns & ns & ns & ns \\
\hline t6, 7,8 & 1.8 & 1.4 & 1.5 & 1.7 & 1.8 & 1.4 & 0.15 & ns & ns & $\mathrm{t}$ & ns & ns & ns \\
\hline t9 & 5.3 & 4.9 & 4.6 & 5.6 & 6.6 & 3.7 & 0.49 & ns & ns & $* *$ & ns & ns & ns \\
\hline $\mathrm{t} 10$ & 4.8 & 3.6 & 1.9 & 6.6 & 5.5 & 3.0 & 0.84 & ns & $* *$ & $\mathrm{t}$ & ns & ns & ns \\
\hline $\mathrm{t} 11(\mathrm{VA})^{\mathrm{f}}$ & 39.7 & 47.0 & 49.0 & 37.5 & 37.3 & 49.2 & 4.69 & ns & ns & ns & ns & ns & ns \\
\hline $\mathrm{t} 12,13,14$ & 2.6 & 2.7 & 2.3 & 3.1 & 3.4 & 2.0 & 0.24 & ns & $\mathrm{t}$ & $* *$ & ns & ns & ns \\
\hline C18:2 & & & & & & & & & & & & & \\
\hline $\mathrm{LA}^{\mathrm{g}}$ & 78.1 & 73.3 & 70.7 & 80.8 & 80.0 & 71.5 & 2.66 & ns & $*$ & $\mathrm{t}$ & ns & ns & ns \\
\hline unknown FA & 3.0 & 3.1 & 2.9 & 3.1 & 2.6 & 3.4 & 0.19 & ns & ns & $*$ & ns & ns & ns \\
\hline$c 9,15$ & 5.3 & 5.5 & 5.5 & 5.3 & 5.8 & 5.0 & 0.33 & ns & ns & ns & ns & ns & ns \\
\hline$c 12,15$ & 1.4 & 1.2 & 1.3 & 1.3 & 1.2 & 1.4 & 0.10 & ns & ns & ns & ns & ns & ns \\
\hline c9 t13 & 1.7 & 1.7 & 1.8 & 1.7 & 1.3 & 2.1 & 0.13 & ns & ns & $* *$ & ns & ns & ns \\
\hline c9t12,t9,12 & 3.2 & 3.4 & 3.1 & 3.5 & 2.9 & 3.7 & 0.22 & ns & ns & $\mathrm{t}$ & ns & ns & ns \\
\hline t8 c13 & 6.2 & 6.3 & 6.1 & 6.4 & 5.8 & 6.7 & 0.56 & ns & ns & ns & ns & ns & ns \\
\hline t11 c15 & 4.7 & 6.3 & 6.3 & 4.7 & 5.6 & 5.5 & 0.66 & ns & ns & ns & ns & ns & ns \\
\hline CLA9 ${ }^{h}$ & 11.3 & 13.2 & 14.1 & 10.4 & 9.9 & 14.6 & 1.52 & ns & ns & ns & ns & ns & ns \\
\hline C18:3 n-3 (ALA) & 27.7 & 33.5 & 35.8 & 25.2 & 29.3 & 31.9 & 2.18 & ns & $*$ & ns & ns & ns & ns \\
\hline C18:3 n-6 & 0.5 & 0.4 & 0.4 & 0.5 & 0.4 & 0.5 & 0.04 & ns & $*$ & $\mathrm{t}$ & ns & ns & ns \\
\hline C20:0 & 2.1 & 2.2 & 2.2 & 2.0 & 1.9 & 2.4 & 0.19 & ns & ns & ns & ns & ns & ns \\
\hline c8 C20:1 & 1.9 & 2.2 & 2.1 & 2.0 & 2.1 & 2.0 & 0.20 & ns & ns & ns & ns & ns & ns \\
\hline C20:2 & 0.7 & 0.7 & 0.6 & 0.7 & 0.8 & 0.5 & 0.04 & ns & ns & $* *$ & ns & ns & ns \\
\hline C22:0 & 0.4 & 0.4 & 0.4 & 0.3 & 0.5 & 0.3 & 0.03 & ns & ns & $* * *$ & ns & ns & ns \\
\hline$C 20: 3 n-6$ & 8.4 & 7.6 & 7.4 & 8.6 & 7.8 & 8.2 & 0.32 & ns & $\mathrm{t}$ & ns & ns & ns & ns \\
\hline$C 20: 3 n-3$ & 0.8 & 0.8 & 1.1 & 0.6 & 0.9 & 0.8 & 0.08 & ns & $* *$ & ns & ns & ns & ns \\
\hline$C 20: 4 n-6$ & 25.1 & 24.4 & 23.2 & 26.4 & 23.2 & 26.2 & 0.86 & ns & $\mathrm{t}$ & $\mathrm{t}$ & ns & ns & ns \\
\hline C23:0 & 1.0 & 1.1 & 1.1 & 1.0 & 1.3 & 0.8 & 0.06 & $\mathrm{t}$ & ns & $* * *$ & ns & $*$ & $\mathrm{t}$ \\
\hline C20:4 n-3 (EPA) & 9.4 & 10.8 & 11.5 & 8.7 & 9.1 & 11.1 & 0.50 & $\mathrm{t}$ & $* *$ & $*$ & ns & ns & ns \\
\hline$C 22: 4 n-6$ & 1.9 & 1.6 & 1.4 & 2.2 & 1.8 & 1.8 & 0.17 & ns & $*$ & ns & ns & ns & ns \\
\hline$C 22: 5 n-3(D P A)^{k}$ & 18.3 & 20.5 & 20.7 & 18.2 & 17.8 & 21.0 & 0.67 & $\mathrm{t}$ & $*$ & $*$ & ns & ns & ns \\
\hline C22:6n-3 (DHA) & 2.6 & 1.8 & 2.5 & 1.9 & 1.4 & 3.0 & 0.23 & $*$ & $\mathrm{t}$ & $* * *$ & ns & $* * *$ & ns \\
\hline Calculated values & & & & & & & & & & & & & \\
\hline Total FA & 2962 & 3313 & 3003 & 3287 & 3326 & 2966 & 229.0 & ns & ns & ns & ns & ns & ns \\
\hline $\mathrm{SFA}^{\mathrm{m}}$ & 1355 & 1535 & 1396 & 1501 & 1515 & 1382 & 107.0 & ns & ns & ns & ns & ns & ns \\
\hline MUFA $^{n}$ & 1397 & 1562 & 1391 & 1576 & 1604 & 1365 & 118.0 & ns & ns & ns & ns & ns & ns \\
\hline PUFA $^{\circ}$ & 210 & 216 & 216 & 210 & 207 & 219 & 6.3 & ns & ns & ns & ns & ns & ns \\
\hline$n-6^{p}$ & 113 & 107 & 103 & 118 & 113 & 108 & 3.4 & ns & $*$ & ns & ns & ns & ns \\
\hline
\end{tabular}




\begin{tabular}{|c|c|c|c|c|c|c|c|c|c|c|c|c|c|}
\hline$n-3^{q}$ & 58.7 & 67.5 & 71.5 & 54.5 & 58.5 & 67.7 & 3.19 & ns & $* *$ & $\mathrm{t}$ & ns & ns & ns \\
\hline$n-3 L^{r}$ & 30.3 & 33.2 & 34.7 & 28.7 & 28.3 & 35.0 & 1.23 & ns & $* *$ & $* *$ & ns & ns & ns \\
\hline$n-6 / n-3^{s}$ & 2.31 & 1.94 & 1.49 & 2.78 & 2.51 & 1.75 & 0.25 & ns & $* *$ & $t$ & ns & ns & ns \\
\hline PUFA/SFA $^{\mathrm{t}}$ & 0.17 & 0.17 & 0.17 & 0.16 & 0.16 & 0.17 & 0.01 & ns & ns & $\mathrm{t}$ & $\mathrm{t}$ & ns & ns \\
\hline
\end{tabular}

${ }^{a}$ Org: organic beef, No-Org: non-organic beef, ${ }^{b}$ Win: Winter-finished, Sum: Summer-finished, 'Su: Supermarket (A or B), Se: Season (Winter or Summer), M: Management (Organic or Non-organic), ${ }^{d * * *}: p<0.0001,{ }^{* *}: p<0.001 ;{ }^{*}: p<0.05, t: p<0.1, n s: p>0.1$

e OA: oleic acid c9 C18:1, ${ }^{\mathrm{f}} \mathrm{VA}$ : vaccenic acid t11 C18:1, ${ }^{\mathrm{g}}$ LA: linoleic acid c9,12 C18:2, ${ }^{\mathrm{h}}$ CLA9: conjugated linoleic acid c9 t11 C18:2, ${ }^{\mathrm{A}}$ ALA: alpha linolenic acid c9, 12 ,

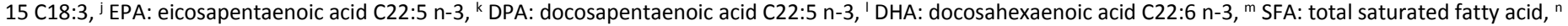
MUFA: total monounsaturated fatty acid, ${ }^{\circ}$ PUFA: total polyunsaturated fatty acid, ${ }^{p} n-6$ : omega- 6 polyunsaturated fatty acid, ${ }^{9} n-3$ : omega-3 polyunsaturated fatty acid, ${ }^{r} \mathrm{n}-3$ LC: omega-3 long-chain polyunsaturated fatty acid, ${ }^{\mathrm{s}} \mathrm{n}-6 / \mathrm{n}-3$ : ratio of omega- 6 polyunsaturated fatty acid to omega-3 polyunsaturated fatty acids, ${ }^{\mathrm{t}}$ PUFA/SFA: ratio of polyunsaturated fatty acid to saturated fatty acid 
Table 2. Fatty acid concentrations (g/Kg total fatty acids) in intramuscular fat of sirloin steaks (mean values for main factors, composite standard errors of means (sem) and ANOVA p-values for main factors and interactions)

\begin{tabular}{|c|c|c|c|c|c|c|c|c|c|c|c|c|c|}
\hline \multirow[b]{3}{*}{ Fatty acid } & \multicolumn{2}{|c|}{ Supermarket } & \multicolumn{2}{|c|}{ Management $^{\mathrm{a}}$} & \multicolumn{2}{|c|}{ Season $^{\mathrm{b}}$} & \multirow[b]{3}{*}{ sem } & \multicolumn{6}{|c|}{$p^{-V_{a l u e s}}{ }^{d}$} \\
\hline & \multirow{2}{*}{$\begin{array}{c}A \\
(n=19)\end{array}$} & \multirow{2}{*}{$\begin{array}{c}B \\
(n=20)\end{array}$} & \multirow{2}{*}{$\begin{array}{c}\text { Org } \\
(n=20)\end{array}$} & \multirow{2}{*}{$\begin{array}{l}\text { No-org } \\
(n=19)\end{array}$} & \multirow{2}{*}{$\begin{array}{l}\text { Win } \\
(n=19)\end{array}$} & \multirow{2}{*}{$\begin{array}{l}\text { Sum } \\
(n=20)\end{array}$} & & \multicolumn{3}{|c|}{ Main factors ${ }^{c}$} & \multicolumn{3}{|c|}{ Interactions } \\
\hline & & & & & & & & Su & $\mathrm{M}$ & Se & SuxM & $\begin{array}{c}\text { SuxS } \\
\mathrm{e}\end{array}$ & MxSe \\
\hline C10:0 & 0.4 & 0.4 & 0.4 & 0.4 & 0.4 & 0.4 & 0.02 & $\mathrm{t}$ & $\mathrm{ns}$ & ns & ns & ns & ns \\
\hline C12:0 & 0.5 & 0.5 & 0.5 & 0.5 & 0.5 & 0.6 & 0.03 & ns & ns & $\mathrm{t}$ & ns & ns & ns \\
\hline C14.0 & 24.6 & 27.4 & 26.3 & 25.7 & 27.1 & 25.0 & 0.74 & $\mathrm{t}$ & ns & ns & ns & ns & ns \\
\hline C14:1 & 5.8 & 6.5 & 5.9 & 6.5 & 6.3 & 6.0 & 0.33 & ns & ns & ns & ns & ns & ns \\
\hline C15:0 & 4.2 & 4.0 & 4.4 & 3.7 & 4.1 & 4.0 & 0.16 & ns & $*$ & ns & ns & ns & ns \\
\hline C16:0 & 270 & 276 & 274 & 272 & 272 & 274 & 2.4 & ns & ns & ns & ns & ns & ns \\
\hline c9 C16:1 & 36.9 & 41.5 & 38.9 & 39.6 & 39.5 & 39.0 & 1.06 & $*$ & ns & ns & ns & ns & ns \\
\hline t9 C16:1 & 4.1 & 4.3 & 4.6 & 3.8 & 3.6 & 4.8 & 0.18 & ns & $* *$ & $* * *$ & ns & $\mathrm{t}$ & ns \\
\hline C17:0 & 9.2 & 8.4 & 9.1 & 8.5 & 9.5 & 8.1 & 0.34 & ns & ns & $*$ & ns & ns & ns \\
\hline C17:1 & 0.9 & 0.9 & 0.9 & 0.9 & 0.8 & 1.0 & 0.07 & ns & ns & ns & ns & ns & ns \\
\hline C18:0 & 148 & 141 & 147 & 142 & 139 & 149 & 2.9 & ns & ns & $\mathrm{t}$ & ns & ns & ns \\
\hline C18:1 & & & & & & & & & & & & & \\
\hline$c 9(O A)^{e}$ & 376 & 370 & 366 & 380 & 386 & 360 & 4.3 & ns & $\mathrm{t}$ & $* * *$ & ns & $\mathrm{t}$ & ns \\
\hline c11 & 18.1 & 18.3 & 17.5 & 19.0 & 16.7 & 19.7 & 0.40 & ns & $*$ & $* * *$ & ns & ns & ns \\
\hline c12 & 1.0 & 0.8 & 0.7 & 1.1 & 0.6 & 1.2 & 0.10 & ns & $*$ & $* * *$ & ns & ns & ns \\
\hline c13 & 2.0 & 2.0 & 1.7 & 2.3 & 2.0 & 2.0 & 0.15 & ns & $\mathrm{t}$ & ns & ns & ns & ns \\
\hline $\mathrm{c} 14+\mathrm{t} 16$ & 1.5 & 1.4 & 1.6 & 1.4 & 1.5 & 1.5 & 0.06 & ns & ns & ns & ns & ns & $\mathrm{t}$ \\
\hline c15 & 0.6 & 0.7 & 0.7 & 0.6 & 0.8 & 0.5 & 0.04 & ns & ns & $* * *$ & ns & ns & ns \\
\hline t6, 7,8 & 0.6 & 0.4 & 0.5 & 0.6 & 0.6 & 0.5 & 0.04 & $*$ & ns & ns & ns & ns & ns \\
\hline t9 & 1.8 & 1.5 & 1.5 & 1.8 & 2.0 & 1.3 & 0.09 & $\mathrm{t}$ & $\mathrm{t}$ & $* * *$ & ns & ns & ns \\
\hline $\mathrm{t} 10$ & 1.7 & 1.1 & 0.7 & 2.1 & 1.6 & 1.1 & 0.25 & ns & $* *$ & ns & ns & ns & ns \\
\hline $\mathrm{t} 11(\mathrm{VA})^{\mathrm{f}}$ & 14.0 & 14.0 & 16.8 & 11.1 & 10.9 & 16.9 & 1.34 & ns & $*$ & $*$ & ns & ns & ns \\
\hline $\mathrm{t} 12,13,14$ & 1.0 & 0.9 & 0.8 & 1.1 & 1.1 & 0.8 & 0.08 & ns & ns & ns & ns & ns & ns \\
\hline C18:2 & & & & & & & & & & & & & \\
\hline $\mathrm{LA}^{\mathrm{g}}$ & 28.3 & 27.0 & 26.0 & 29.3 & 28.6 & 26.8 & 1.70 & ns & ns & ns & ns & ns & ns \\
\hline unknown FA & 1.1 & 1.0 & 1.0 & 1.0 & 0.9 & 1.2 & 0.05 & ns & ns & $* *$ & ns & ns & ns \\
\hline$c 9,15$ & 1.8 & 1.8 & 1.9 & 1.7 & 1.8 & 1.7 & 0.07 & ns & ns & ns & ns & ns & ns \\
\hline$c 12,15$ & 0.5 & 0.4 & 0.5 & 0.4 & 0.4 & 0.5 & 0.03 & ns & ns & ns & $*$ & ns & ns \\
\hline c9t13 & 0.6 & 0.5 & 0.6 & 0.5 & 0.4 & 0.7 & 0.04 & ns & ns & $* * *$ & ns & ns & ns \\
\hline c9t12,t9, 12 & 1.1 & 1.1 & 1.1 & 1.1 & 0.9 & 1.3 & 0.05 & ns & ns & $* * *$ & ns & ns & ns \\
\hline t8 c13 & 2.1 & 1.9 & 2.0 & 1.9 & 1.6 & 2.3 & 0.09 & ns & ns & $* * *$ & ns & ns & ns \\
\hline t11 c15 & 1.6 & 1.8 & 2.1 & 1.3 & 1.6 & 1.8 & 0.16 & ns & $*$ & ns & ns & ns & ns \\
\hline $\mathrm{CLA} 9^{\mathrm{h}}$ & 3.8 & 3.8 & 4.7 & 2.8 & 2.7 & 4.8 & 0.37 & ns & $* *$ & $* *$ & ns & ns & ns \\
\hline C18:3 n-3 (ALA) ${ }^{i}$ & 9.7 & 11.0 & 12.5 & 8.1 & 9.5 & 11.2 & 0.64 & ns & $* * *$ & $\mathrm{t}$ & ns & ns & ns \\
\hline C18:3 n-6 & 0.2 & 0.2 & 0.2 & 0.2 & 0.2 & 0.2 & 0.02 & ns & ns & ns & ns & ns & ns \\
\hline C20:0 & 0.7 & 0.6 & 0.7 & 0.6 & 0.5 & 0.8 & 0.03 & ns & $\mathrm{t}$ & $* * *$ & ns & ns & $\mathrm{t}$ \\
\hline c8 C20:1 & 0.6 & 0.6 & 0.7 & 0.6 & 0.6 & 0.7 & 0.03 & ns & $*$ & ns & ns & ns & ns \\
\hline C20:2 & 0.2 & 0.3 & 0.2 & 0.3 & 0.3 & 0.2 & 0.03 & ns & ns & $\mathrm{t}$ & ns & ns & ns \\
\hline C22:0 & 0.1 & 0.1 & 0.1 & 0.1 & 0.2 & 0.1 & 0.01 & ns & $\mathrm{t}$ & $* * *$ & ns & ns & ns \\
\hline$C 20: 3 n-6$ & 3.0 & 2.9 & 2.7 & 3.3 & 2.9 & 3.1 & 0.22 & ns & ns & ns & ns & ns & ns \\
\hline$C 20: 3 n-3$ & 0.3 & 0.3 & 0.4 & 0.2 & 0.3 & 0.3 & 0.03 & ns & $* * *$ & ns & ns & ns & ns \\
\hline$C 20: 4 n-6$ & 9.5 & 9.2 & 8.7 & 10.1 & 8.6 & 10.0 & 0.70 & ns & ns & ns & ns & ns & ns \\
\hline C23:0 & 0.4 & 0.4 & 0.4 & 0.4 & 0.5 & 0.3 & 0.03 & ns & ns & $* *$ & ns & $*$ & ns \\
\hline$C 20: 5 n-3(E P A)^{j}$ & 3.5 & 4.1 & 4.2 & 3.3 & 3.4 & 4.2 & 0.32 & ns & ns & ns & ns & ns & ns \\
\hline$C 22: 4 n-6$ & 0.7 & 0.6 & 0.5 & 0.8 & 0.6 & 0.7 & 0.08 & ns & $*$ & ns & ns & ns & ns \\
\hline$C 22: 5 n-3(D P A)^{k}$ & 6.7 & 7.5 & 7.5 & 6.7 & 6.3 & 7.9 & 0.45 & ns & ns & $\mathrm{t}$ & ns & ns & ns \\
\hline C22:6n-3 (DHA) & 1.0 & 0.6 & 0.9 & 0.7 & 0.5 & 1.1 & 0.08 & $* *$ & $\mathrm{t}$ & $* * *$ & ns & $* * *$ & ns \\
\hline Calculated values & & & & & & & & & & & & & \\
\hline $\mathrm{SFA}^{\mathrm{m}}$ & 461 & 463 & 467 & 456 & 456 & 467 & 3.7 & ns & ns & ns & ns & ns & ns \\
\hline MUFA $^{n}$ & 465 & 463 & 458 & 471 & 474 & 456 & 4.4 & ns & ns & $*$ & ns & ns & ns \\
\hline PUFA $^{\circ}$ & 71.2 & 71.5 & 72.4 & 70.3 & 68.2 & 74.5 & 3.36 & ns & ns & ns & ns & ns & ns \\
\hline$n-6^{p}$ & 4.2 & 4.0 & 3.8 & 4.3 & 4.1 & 4.1 & 0.26 & ns & ns & ns & ns & ns & ns \\
\hline$n-3^{q}$ & 2.1 & 2.4 & 2.5 & 1.9 & 2.0 & 2.5 & 0.13 & ns & $*$ & $*$ & ns & $\mathrm{t}$ & ns \\
\hline$n-3 L^{r}$ & 1.1 & 1.2 & 1.3 & 1.1 & 1.0 & 1.3 & 0.08 & ns & ns & $\mathrm{t}$ & ns & $\mathrm{t}$ & ns \\
\hline
\end{tabular}


a Org: organic beef, No-Org: non-organic beef, ${ }^{b} W i n:$ Winter-finished, Sum: Summer-finished, 'Su: Supermarket (A or B), Se: Season (Winter or Summer), M: Management (Organic or Non-organic), ${ }^{d * * *}$ : $p<0.0001,{ }^{* *}: p<0.001 ;{ }^{*}: p<0.05, t: p<0.1, n s: p>0.1$

e OA: oleic acid c9 C18:1, ${ }^{\mathrm{f}}$ VA: vaccenic acid t11 C18:1, ${ }^{\mathrm{g}}$ LA: linoleic acid c9,12 C18:2, ${ }^{\mathrm{h}} \mathrm{CLA9}$ : conjugated linoleic acid c9 t11 C18:2, ${ }^{i}$ ALA: alpha linolenic acid $\mathrm{c9}, 12,15$ C18:3, ${ }^{j}$ EPA: eicosapentaenoic acid C20:5 n-3, ${ }^{k}$ DPA: docosapentaenoic acid C22:5 n-3, ' DHA: docosahexaenoic acid C22:6 n-3, ${ }^{m}$ SFA: total saturated fatty acid, ${ }^{n}$ MUFA: total monounsaturated fatty acid, ${ }^{\circ}$ PUFA: total polyunsaturated fatty acid, ${ }^{\mathrm{p}} \mathrm{n}-6$ : omega- 6 polyunsaturated fatty acid, ${ }^{\mathrm{a}} \mathrm{n}-3$ : omega-3 polyunsaturated fatty acid, ' $n-3$ LC: omega-3 long-chain polyunsaturated fatty acid 
Table 3. Fatty acid concentrations (g/Kg total fatty acids) in subcutaneous fat from sirloin steaks (mean values for main factors, composite standard errors of means (sem) and ANOVA p-values for main factors and interactions)

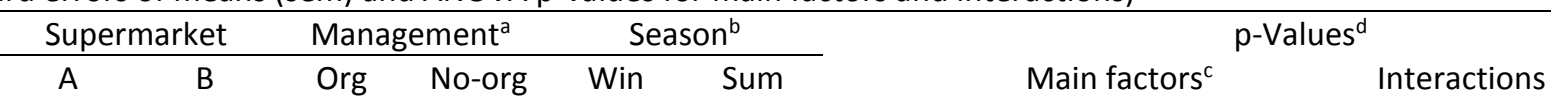

Fatty acid $\quad(n=19) \quad(n=20) \quad(n=20) \quad(n=19) \quad(n=19) \quad(n=20) \quad$ sem $\quad$ Su $\quad M \quad$ Se $\quad$ SuxM SuxS MxSe

\begin{tabular}{|c|c|c|c|c|c|c|c|c|c|c|c|c|c|}
\hline C10:0 & 0.35 & 0.44 & 0.43 & 0.37 & 0.36 & 0.43 & 0.02 & $*$ & ns & $\mathrm{t}$ & ns & ns & ns \\
\hline C12:0 & 0.7 & 0.9 & 0.8 & 0.7 & 0.7 & 0.8 & 0.04 & $* *$ & ns & $*$ & ns & ns & ns \\
\hline C14.0 & 36.0 & 42.1 & 40.8 & 37.4 & 39.4 & 38.9 & 0.99 & $* *$ & $\mathrm{t}$ & ns & ns & ns & ns \\
\hline C14:1 & 14.6 & 15.7 & 13.8 & 16.6 & 15.7 & 14.7 & 0.83 & ns & ns & ns & ns & ns & ns \\
\hline C16:0 & 279 & 287 & 285 & 282 & 282 & 285 & 2.9 & ns & ns & ns & ns & ns & ns \\
\hline c9 C16:1 & 58.8 & 62.8 & 57.1 & 64.8 & 61.7 & 60.1 & 2.23 & ns & ns & ns & ns & ns & ns \\
\hline C17:1 & $n d^{t}$ & $n d^{t}$ & $n d^{t}$ & $n d^{t}$ & $n d^{t}$ & $n d^{t}$ & & & & & & & \\
\hline C18:0 & 124 & 121 & 132 & 113 & 114 & 131 & 4.5 & ns & $*$ & $\mathrm{t}$ & ns & ns & ns \\
\hline \multicolumn{14}{|l|}{ C18:1 } \\
\hline$c 9(O A)^{e}$ & 378 & 361 & 354 & 385 & 384 & 355 & 5.7 & $\mathrm{t}$ & $* *$ & $* *$ & ns & ns & ns \\
\hline c11 & 17.5 & 16.5 & 15.1 & 19.0 & 17.5 & 16.6 & 0.60 & ns & $* *$ & ns & ns & ns & ns \\
\hline$t 6,7,8$ & 1.0 & 0.9 & 0.9 & 0.9 & 1.0 & 0.9 & 0.06 & ns & ns & ns & ns & ns & ns \\
\hline t9 & 1.3 & 1.2 & 1.2 & 1.3 & 1.4 & 1.1 & 0.07 & ns & ns & $*$ & ns & ns & ns \\
\hline $\mathrm{t} 10$ & 2.6 & 1.3 & 1.0 & 3.0 & 2.5 & 1.5 & 0.38 & $\mathrm{t}$ & $* *$ & $\mathrm{t}$ & ns & ns & ns \\
\hline $\mathrm{t} 11(\mathrm{VA})^{\mathrm{f}}$ & 19.2 & 22.4 & 26.5 & 14.9 & 16.2 & 25.3 & 2.35 & ns & $*$ & $*$ & ns & ns & ns \\
\hline $\mathrm{t} 12,13,14$ & 1.2 & 1.3 & 1.3 & 1.2 & 1.4 & 1.1 & 0.10 & ns & ns & ns & $\mathrm{t}$ & ns & ns \\
\hline \multicolumn{14}{|l|}{ C18:2 } \\
\hline $\mathrm{LA}^{\mathrm{g}}$ & 8.2 & 7.1 & 7.4 & 7.9 & 8.0 & 7.3 & 0.35 & ns & ns & ns & ns & ns & ns \\
\hline unknown FA & 0.8 & 0.8 & 0.8 & 0.8 & 0.7 & 0.8 & 0.04 & ns & ns & $*$ & $\mathrm{t}$ & $* *$ & ns \\
\hline$c 9,15$ & 1.8 & 2.0 & 2.0 & 1.8 & 2.1 & 1.7 & 0.07 & $\mathrm{t}$ & $\mathrm{t}$ & $*$ & ns & $\mathrm{t}$ & ns \\
\hline $\mathrm{c} 12,15$ & 0.4 & 0.3 & 0.3 & 0.4 & 0.4 & 0.4 & 0.03 & ns & ns & ns & ns & ns & ns \\
\hline c9 t13 & 0.9 & 0.8 & 0.9 & 0.7 & 0.5 & 1.1 & 0.08 & ns & ns & $* * *$ & ns & ns & ns \\
\hline c8 C20:1 & 1.0 & 1.1 & 1.1 & 1.0 & 1.1 & 1.1 & 0.04 & ns & $\mathrm{t}$ & ns & ns & ns & ns \\
\hline $\mathrm{C} 22: 0$ & 0.18 & 0.17 & 0.22 & 0.12 & 0.13 & 0.22 & 0.02 & ns & $* *$ & $* *$ & $\mathrm{t}$ & ns & ns \\
\hline$C 20: 3 n-6$ & 0.44 & 0.31 & 0.39 & 0.35 & 0.39 & 0.36 & 0.03 & $*$ & ns & ns & ns & ns & ns \\
\hline$C 20: 3 n-3$ & 0.15 & 0.17 & 0.19 & 0.13 & 0.13 & 0.19 & 0.02 & ns & $\mathrm{t}$ & $t$ & ns & ns & ns \\
\hline$C 20: 4 n-6$ & 0.28 & 0.25 & 0.24 & 0.29 & 0.18 & 0.34 & 0.02 & ns & $\mathrm{t}$ & $* * *$ & ns & ns & ns \\
\hline $\mathrm{C} 23: 0$ & 0.09 & 0.09 & 0.10 & 0.08 & 0.09 & 0.09 & 0.01 & ns & $\mathrm{t}$ & ns & ns & ns & $*$ \\
\hline$C 20: 5 n-3(E P A)^{j}$ & 0.06 & 0.06 & 0.08 & 0.05 & 0.05 & 0.07 & 0.01 & ns & $\mathrm{t}$ & ns & ns & ns & ns \\
\hline C22:5n-3 (DPA) ${ }^{k}$ & 0.39 & 0.59 & 0.59 & 0.40 & 0.37 & 0.61 & 0.05 & $*$ & $*$ & $* *$ & ns & ns & $\mathrm{t}$ \\
\hline C22:6n-3 (DHA) $)^{\prime}$ & $n d^{t}$ & $n d^{t}$ & $n d^{t}$ & $n d^{t}$ & $n d^{t}$ & $n d^{t}$ & & & & & & & \\
\hline \multicolumn{14}{|l|}{ Calculated values } \\
\hline SFA' & 465 & 477 & 486 & 455 & 460 & 482 & 5.8 & ns & $* *$ & $*$ & ns & ns & ns \\
\hline MUFA $^{\mathrm{m}}$ & 512 & 501 & 490 & 523 & 519 & 494 & 6.0 & ns & $* *$ & $*$ & ns & ns & ns \\
\hline PUFA $^{n}$ & 19.5 & 18.9 & 20.0 & 18.3 & 18.1 & 20.2 & 0.51 & ns & $\mathrm{t}$ & $*$ & ns & ns & ns \\
\hline$n-6^{\circ}$ & 9.0 & 7.7 & 8.0 & 8.6 & 8.7 & 8.0 & 0.37 & ns & ns & ns & ns & ns & ns \\
\hline$n-3^{p}$ & 6.9 & 7.6 & 8.5 & 5.9 & 6.9 & 7.6 & 0.45 & ns & $* *$ & ns & ns & ns & ns \\
\hline$n-3$ LC & 0.46 & 0.65 & 0.66 & 0.45 & 0.42 & 0.69 & 0.05 & $*$ & $*$ & $* *$ & ns & ns & $\mathrm{t}$ \\
\hline$n-6 / n-3^{r}$ & 1.5 & 1.2 & 1.0 & 1.7 & 1.4 & 1.3 & 0.13 & ns & $* *$ & ns & ns & ns & ns \\
\hline PUFA/SFA & 0.042 & 0.040 & 0.041 & 0.040 & 0.039 & 0.042 & 0.001 & ns & ns & ns & ns & ns & ns \\
\hline
\end{tabular}


a Org: organic beef, No-Org: non-organic beef, ${ }^{b}$ Win: Winter-finished, Sum: Summer-finished, 'Su: Supermarket (A or B), Se: Season (Winter or Summer), M: Management (Organic or Non-organic), ${ }^{d * * *}: p<0.0001,{ }^{* *}: p<0.001 ;{ }^{*}: p<0.05, t: p<0.1, n s: p>0.1$

e OA: oleic acid c9C18:1, ${ }^{\mathrm{f}}$ VA: vaccenic acid t11 C18:1, $\mathrm{g}$ LA: linoleic acid c9,12 C18:2, ${ }^{\mathrm{h}}$ CLA9: conjugated linoleic acid c9t11 C18:2, ${ }^{\mathrm{A}}$ ALA: alpha linolenic acid c9,12,15 C18:3, ${ }^{j}$ EPA: eicosapentaenoic acid C20:5, ${ }^{k}$ DPA: docosapentaenoic acid (C22:5 n-3 ), ' SFA: total saturated fatty acid, ${ }^{m}$ MUFA: total monounsaturated fatty acid, ${ }^{n}$ PUFA: total polyunsaturated fatty acid, ${ }^{\circ} \mathrm{n}-6$ : omega- 6 polyunsaturated fatty acid, ${ }^{\mathrm{p}} \mathrm{n}-3$ : omega-3 polyunsaturated fatty acid, ${ }^{a} \mathrm{n}-3$ LC: omega-3 long-chain polyunsaturated fatty acid, ${ }^{\mathrm{r}} \mathrm{n}-6 / \mathrm{n}-3$ : ratio of omega- 6 polyunsaturated fatty acid to omega-3 polyunsaturated fatty acids, ${ }^{\mathrm{s}}$ PUFA/SFA: ratio of polyunsaturated fatty acid to saturated fatty acid and tnone detected 
Table 4. Relationship between fatty acid concentrations in intramuscular fat (IMF) and subcutaneous fat (SCF) (mean values (IMF:SCF ratios) for main factors, standard errors of means (sem) and ANOVA p-values for main factors and interactions)

\begin{tabular}{|c|c|c|c|c|c|c|c|c|c|c|c|c|c|}
\hline \multirow[b]{3}{*}{ Fatty acid } & \multicolumn{2}{|c|}{ Supermarket } & \multicolumn{2}{|c|}{ Management $^{\mathrm{a}}$} & \multicolumn{2}{|c|}{ Season $^{b}$} & \multirow[b]{3}{*}{ sem } & \multicolumn{6}{|c|}{$p^{p-V_{a l u e s}}{ }^{d}$} \\
\hline & \multirow{2}{*}{$\begin{array}{c}A \\
(n=19)\end{array}$} & \multirow{2}{*}{$\begin{array}{c}B \\
(n=20)\end{array}$} & \multirow{2}{*}{$\begin{array}{c}\text { Org } \\
(n=20)\end{array}$} & \multirow{2}{*}{$\begin{array}{l}\text { No-org } \\
(n=19)\end{array}$} & \multirow{2}{*}{$\begin{array}{c}\text { Sum } \\
(n=19)\end{array}$} & \multirow{2}{*}{$\begin{array}{c}\text { Win } \\
(n=20)\end{array}$} & & \multicolumn{3}{|c|}{ Main factors ${ }^{c}$} & \multicolumn{3}{|c|}{ Interactions } \\
\hline & & & & & & & & $\mathrm{Su}$ & $\mathrm{M}$ & $\mathrm{Se}$ & SuxM & SuxSe & $\mathrm{MxSe}$ \\
\hline C10:0 & 1.09 & 1.04 & 1.03 & 1.09 & 1.10 & 1.03 & 0.055 & ns & ns & ns & ns & ns & ns \\
\hline C14.0 & 0.69 & 0.65 & 0.65 & 0.69 & 0.70 & 0.65 & 0.017 & $\mathrm{t}$ & ns & ns & ns & ns & ns \\
\hline C14:1 & 0.44 & 0.42 & 0.44 & 0.43 & 0.44 & 0.42 & 0.029 & ns & ns & ns & ns & ns & ns \\
\hline c9 C16:1 & 0.66 & 0.68 & 0.69 & 0.65 & 0.68 & 0.66 & 0.027 & ns & ns & ns & ns & ns & ns \\
\hline t9 C16:1 & 0.92 & 0.94 & 0.92 & 0.94 & 0.92 & 0.94 & 0.022 & ns & ns & ns & ns & ns & ns \\
\hline C17:0 & 0.95 & 0.92 & 0.90 & 0.97 & 0.92 & 0.94 & 0.029 & ns & ns & ns & ns & ns & ns \\
\hline C18:0 & 1.24 & 1.20 & 1.15 & 1.30 & 1.27 & 1.18 & 0.039 & ns & $\mathrm{t}$ & ns & ns & ns & ns \\
\hline \multicolumn{14}{|l|}{ C18:1 } \\
\hline $\mathrm{c} 14+\mathrm{t} 16$ & 0.68 & 0.68 & 0.64 & 0.72 & 0.67 & 0.69 & 0.023 & ns & $\mathrm{t}$ & ns & $*$ & ns & ns \\
\hline c15 & 0.65 & 0.69 & 0.66 & 0.67 & 0.72 & 0.62 & 0.027 & ns & ns & $\mathrm{t}$ & $* *$ & ns & ns \\
\hline t6, 7,8 & 0.63 & 0.61 & 0.53 & 0.71 & 0.60 & 0.64 & 0.056 & ns & ns & ns & ns & ns & ns \\
\hline t9 & 1.44 & 1.39 & 1.37 & 1.46 & 1.39 & 1.43 & 0.096 & ns & ns & ns & ns & ns & ns \\
\hline $\mathrm{t} 10$ & 0.69 & 1.01 & 0.72 & 0.99 & 0.67 & 1.02 & 0.112 & ns & ns & $\mathrm{t}$ & ns & ns & ns \\
\hline t11 (VA) $)^{f}$ & 0.79 & 0.66 & 0.69 & 0.76 & 0.71 & 0.73 & 0.028 & $*$ & ns & ns & ns & ns & ns \\
\hline $\mathrm{t} 12,13,14$ & 0.94 & 0.87 & 0.86 & 0.95 & 0.89 & 0.92 & 0.110 & ns & ns & ns & ns & ns & ns \\
\hline \multicolumn{14}{|l|}{ C18:2 } \\
\hline$L A^{g}$ & 3.50 & 3.97 & 3.62 & 3.87 & 3.60 & 3.88 & 0.230 & ns & ns & ns & ns & ns & ns \\
\hline unknown FA & 1.52 & 1.29 & 1.40 & 1.41 & 1.36 & 1.45 & 0.077 & ns & ns & ns & ns & ns & ns \\
\hline$c 9,15$ & 1.05 & 0.94 & 1.02 & 0.98 & 0.92 & 1.07 & 0.059 & ns & ns & ns & ns & ns & ns \\
\hline C20:0 & 0.73 & 0.66 & 0.66 & 0.73 & 0.67 & 0.71 & 0.038 & ns & ns & ns & ns & ns & ns \\
\hline c8 C20:1 & 0.62 & 0.61 & 0.64 & 0.60 & 0.56 & 0.67 & 0.029 & ns & ns & $\mathrm{t}$ & ns & ns & ns \\
\hline $\mathrm{C} 22: 0$ & 1.27 & 0.96 & 0.88 & 1.36 & 1.65 & 0.61 & 0.138 & ns & $*$ & $* * *$ & ns & ns & ns \\
\hline$C 20: 3 n-6$ & 8.17 & 11.56 & 8.72 & 11.16 & 8.00 & 11.73 & 1.020 & $\mathrm{t}$ & ns & $\mathrm{t}$ & ns & ns & ns \\
\hline$C 20: 3 n-3$ & 2.07 & 1.94 & 2.18 & 1.82 & 2.29 & 1.73 & 0.194 & ns & ns & ns & ns & ns & ns \\
\hline$C 20: 4 n-6$ & 36.2 & 43.5 & 41.1 & 38.8 & 49.2 & 31.2 & 3.18 & ns & ns & $* *$ & ns & $*$ & ns \\
\hline $\mathrm{C} 23: 0$ & 4.95 & 5.43 & 5.27 & 5.12 & 6.35 & 4.10 & 0.563 & ns & ns & $*$ & ns & $\mathrm{t}$ & ns \\
\hline$C 20: 5 n-3(E P A)^{j}$ & 72.5 & 87.6 & 69.3 & 91.8 & 78.3 & 82.1 & 9.81 & ns & ns & ns & ns & ns & ns \\
\hline$C 22: 5 n-3(D P A)^{k}$ & 31.2 & 17.6 & 26.3 & 22.0 & 20.3 & 28.0 & 5.75 & ns & ns & ns & ns & ns & ns \\
\hline Fatty acid groups & & & & & & & & & & & & & \\
\hline SFA' & 0.99 & 0.97 & 0.96 & 1.00 & 0.99 & 0.97 & 0.010 & ns & $*$ & ns & ns & ns & ns \\
\hline MUFA $^{\mathrm{m}}$ & 0.91 & 0.93 & 0.94 & 0.90 & 0.91 & 0.92 & 0.009 & ns & $*$ & ns & ns & ns & ns \\
\hline PUFA $^{n}$ & 3.60 & 3.75 & 3.56 & 3.81 & 3.66 & 3.69 & 0.176 & ns & ns & ns & ns & ns & ns \\
\hline$n-6^{\circ}$ & 4.11 & 4.62 & 4.18 & 4.57 & 4.27 & 4.46 & 0.271 & ns & ns & ns & ns & ns & ns \\
\hline$n-3^{p}$ & 2.29 & 2.21 & 2.17 & 2.33 & 2.04 & 2.45 & 0.123 & ns & ns & ns & ns & ns & ns \\
\hline$n-3 L^{q}$ & 33.0 & 24.0 & 27.7 & 29.1 & 26.7 & 30.0 & 3.77 & ns & ns & ns & ns & ns & ns \\
\hline
\end{tabular}

${ }^{a}$ Org: organic beef, No-Org: non-organic beef, ${ }^{b}$ Win: Winter-finished, Sum: Summer-finished, 'Su: Supermarket (A or B), Se: Season (Winter or Summer), M: Management (Organic or Non-organic), ${ }^{d * * *}: p<0.0001,{ }^{* *}: p<0.001 ;{ }^{*}: p<0.05, t: p<0.1, n s: p>0.1$

e OA: oleic acid c9C18:1, ${ }^{f}$ VA: vaccenic acid t11C18:1, g LA: linoleic acid c9,12 C18:2, ${ }^{\text {h } C L A 9: ~ c o n j u g a t e d ~ l i n o l e i c ~ a c i d ~ c 9 t 11 ~ C 18: 2, ~}{ }^{i}$ ALA: alpha linolenic acid c9,12,15 C18:3, ${ }^{j}$ EPA: eicosapentaenoic acid C20:5, ${ }^{k}$ DPA: docosapentaenoic acid (C22:5 n-3), ' SFA: total saturated fatty acid, ${ }^{m}$ MUFA: total monounsaturated fatty acid, ${ }^{n}$ PUFA: total polyunsaturated fatty acid, ${ }^{\circ} \mathrm{n}-6$ : omega- 6 polyunsaturated fatty acid, ${ }^{\mathrm{p}} \mathrm{n}-3$ : omega-3 polyunsaturated fatty acid, ${ }^{\mathrm{a}} \mathrm{n}-3 \mathrm{LC}$ : omega-3 long-chain polyunsaturated fatty acid, ${ }^{r} \mathrm{n}-6 / \mathrm{n}-3$ : ratio of omega- 6 polyunsaturated fatty acid to omega-3 polyunsaturated fatty acids, ${ }^{\mathrm{s}}$ PUFA/SFA: ratio of polyunsaturated fatty acid to saturated fatty acid 

Table 5. Correlation between concentration ratios in intramuscular fat and subcutaneous fat for individual and groups of fatty acids with total fatty acid content of intramuscular fat (Pearson Correlation coefficients and $p$ values)

\begin{tabular}{ccc} 
Mean Ratio & $\begin{array}{c}\text { Pearson correlation } \\
\text { coefficient to TFA }\end{array}$ & $\begin{array}{c}\text { p value for } \\
\text { correlation }^{b}\end{array}$ \\
\hline
\end{tabular}

Individual fatty acids showing a positive correlation

$\begin{array}{lll}\text { C14:0 } & 0.67 & 0.37 \\ \text { C17:0 } & 0.93 & 0.33\end{array}$

Fatty acid groups showing positive correlation MUFA $^{c}$

0.93

0.35

Individual fatty acids showing negative correlation

$\begin{array}{lcc}\mathrm{LA}^{d} & 3.74 & -0.70 \\ \mathrm{ALA}^{\mathrm{e}} & 1.62 & -0.50 \\ \mathrm{C} 20: 4 n-6 & 39.97 & -0.45 \\ \mathrm{c} 125 & 1.29 & -0.38 \\ \mathrm{t} 124 & 0.91 & -0.36 \\ \mathrm{C} 20: 3 n-6 & 9.91 & -0.35 \\ \text { C23:0 }^{f} & 5.20 & -0.35 \\ \text { EPA }^{f} & 80.25 & -0.35\end{array}$

Fatty acid groups showing negative correlation

\begin{tabular}{lccc}
$\mathrm{n}-6^{\mathrm{g}}$ & 4.29 & -0.72 & $* * *$ \\
$\mathrm{PUFA}^{\mathrm{h}}$ & 2.20 & -0.67 & $* * *$ \\
$\mathrm{n}-3^{\mathrm{i}}$ & 2.18 & -0.60 & $* * *$ \\
$\mathrm{n}-3 \mathrm{LC}^{\mathrm{j}}$ & 26.42 & -0.35 & $*$ \\
\hline
\end{tabular}

aTFA: total fatty acids in intramuscular fat, ${ }^{b * * *}: p<0.0001,{ }^{* *}: p<0.001 ; *: p<0.05$,

'MUFA: total monounsaturated fatty acid, 'LA: linoleic acid c9,12 C18:2, "ALA: alpha linolenic acid c9,12,15 C18:3, fEPA: eicosapentaenoic acid C20:5 n-3, $\mathrm{g}$ n-6: omega- 6 polyunsaturated fatty acid,

hPUFA: total polyunsaturated fatty acid, 'n-3: omega -3 polyunsaturated fatty acid, 'in-3 LC: omega3 long-chain polyunsaturated fatty acid 
Table 6. Theoretical of fatty acid intake from a sirloin steak composed of $225 \mathrm{~g}$ of muscles longissimus and $10 \mathrm{~g}$ of total fatty acids from subcutaneous adipose tissue and contribution towards recommended dietary guideline (mean intake (mg) and standard errors of means, with \% from subcutaneous fat (SCF) in italics)

\begin{tabular}{|c|c|c|c|c|c|c|c|c|c|}
\hline & \multicolumn{4}{|c|}{ Winter finished } & \multicolumn{4}{|c|}{ Summer finished } & \multirow[b]{3}{*}{ sem $^{a}$} \\
\hline & \multirow{2}{*}{$\begin{array}{l}\text { Organic } \\
\text { mean }\end{array}$} & \multicolumn{3}{|c|}{ Non-organic } & \multicolumn{2}{|c|}{ Organic } & \multicolumn{2}{|c|}{ Non-Organic } & \\
\hline & & $\begin{array}{c}\% \\
\text { from } \\
\text { SCF }\end{array}$ & mean & $\begin{array}{l}\% \\
\text { from } \\
\text { SCF }\end{array}$ & mean & $\begin{array}{l}\% \\
\text { from } \\
\text { SCF }\end{array}$ & mean & $\begin{array}{l}\% \\
\text { from } \\
\text { SCF }\end{array}$ & \\
\hline Total FA ${ }^{b}$ & 17165 & $60 \%$ & 17833 & $59 \%$ & 16347 & $62 \%$ & 17002 & $61 \%$ & 515 \\
\hline$O A^{c}$ & 6442 & $59 \%$ & 7147 & $59 \%$ & 5649 & $61 \%$ & 6294 & $61 \%$ & 233 \\
\hline$V^{d}$ & $230^{\mathrm{ab}}$ & $69 \%$ & $191^{\mathrm{b}}$ & $65 \%$ & $456^{\mathrm{a}}$ & $70 \%$ & $272^{\mathrm{ab}}$ & $67 \%$ & 31 \\
\hline $\mathrm{LA}^{\mathrm{e}}$ & 242 & $32 \%$ & 281 & $29 \%$ & 223 & $31 \%$ & 243 & $31 \%$ & 8.6 \\
\hline CLA9 ${ }^{f}$ & $93^{a b}$ & $75 \%$ & $78^{b}$ & $76 \%$ & $160^{\mathrm{a}}$ & $74 \%$ & $112^{\mathrm{ab}}$ & $77 \%$ & 11 \\
\hline $\mathrm{ALA}^{\mathrm{g}}$ & $156^{\mathrm{ab}}$ & $51 \%$ & $100^{b}$ & $52 \%$ & $158^{a}$ & $48 \%$ & $119^{\mathrm{ab}}$ & $49 \%$ & 8.3 \\
\hline $\mathrm{EPA}^{\mathrm{h}}$ & $24^{\mathrm{ab}}$ & $3 \%$ & $17^{\mathrm{b}}$ & $2 \%$ & $29^{a}$ & $3 \%$ & $23^{\mathrm{ab}}$ & $3 \%$ & 1.2 \\
\hline$D A^{i}$ & $48^{\mathrm{ab}}$ & $8 \%$ & $40^{\mathrm{b}}$ & $9 \%$ & $57^{a}$ & $13 \%$ & $49^{a b}$ & $9 \%$ & 1.8 \\
\hline $\mathrm{DHA}^{\mathrm{j}}$ & $3.7^{\mathrm{bc}}$ & $0 \%$ & $2.5^{c}$ & $0 \%$ & $7.5^{\mathrm{a}}$ & $0 \%$ & $5.8^{\mathrm{ab}}$ & $0 \%$ & 0.5 \\
\hline SFA ${ }^{k}$ & 8079 & $61 \%$ & 7929 & $58 \%$ & 78231 & $64 \%$ & 7857 & $62 \%$ & 250 \\
\hline MUFA' & 8330 & $62 \%$ & 9203 & $61 \%$ & 7604 & $64 \%$ & 8313 & $63 \%$ & 281 \\
\hline PUFA $^{m}$ & $815^{a b}$ & $24 \%$ & $752^{b}$ & $23 \%$ & $921^{a}$ & $23 \%$ & $832^{\mathrm{ab}}$ & $24 \%$ & 23 \\
\hline$n-6^{n}$ & 332 & $6.1 \%$ & 389 & $6.4 \%$ & 336 & $9.2 \%$ & 363 & $6.3 \%$ & 10 \\
\hline$n-3^{\circ}$ & $322^{a}$ & $43 \%$ & $224^{b}$ & $42 \%$ & $344^{a}$ & $42 \%$ & $272^{\mathrm{ab}}$ & $40 \%$ & 14 \\
\hline$n-3 L C^{p}$ & $76^{a b}$ & $6.1 \%$ & $59^{b}$ & $6.4 \%$ & $94^{a}$ & $9.2 \%$ & $78^{\mathrm{ab}}$ & $6.3 \%$ & 3.1 \\
\hline$n-6: n-3^{q}$ & $1.07^{b}$ & & $2.14^{\mathrm{a}}$ & & $1.01^{b}$ & & $1.51^{\mathrm{ab}}$ & & 0.133 \\
\hline \multicolumn{10}{|c|}{ Contribution towards recommended daily dietary guidelines } \\
\hline SFA I $I^{r}$ & $36 \%$ & & $35 \%$ & & $35 \%$ & & $35 \%$ & & \\
\hline ALA $I^{s}$ & $35 \%$ & & $23 \%$ & & $36 \%$ & & $27 \%$ & & \\
\hline$n-3 I^{t}$ & $29 \%$ & & $20 \%$ & & $31 \%$ & & $24 \%$ & & \\
\hline$n-3 L C I^{u}$ & $30 \%$ & & $24 \%$ & & $38 \%$ & & $31 \%$ & & \\
\hline
\end{tabular}

a: standard errors of means, btotal FA: total fatty acids, ${ }^{\mathrm{c}}$ OA: oleic acid c9 C18:1, d VA: vaccenic acid t11 C18:1, e LA: linoleic acid c9,12 C18:2, ${ }^{\mathrm{f} C L A 9:}$ conjugated linoleic acid c9 t11 C18:2, ${ }^{\mathrm{g} A L A}$ : alpha linolenic acid c9,12,15 C18:3, ${ }^{\mathrm{h}}$ EPA: eicosapentaenoic acid C20:5 n-3 , 'DPA: docosapentaenoic acid C22:5 n-3, iDHA: docosahexaenoic acid C22:6 n-3, kSFA: total saturated fatty acid, 'MUFA: total monounsaturated fatty acid, mPUFA: total polyunsaturated fatty acid, ${ }^{n} \mathrm{n}-6$ : omega- 6 polyunsaturated fatty acid, ${ }^{\circ} \mathrm{n}-3$ : omega-3 polyunsaturated fatty acid, ${ }^{\mathrm{p}} \mathrm{n}-3 \mathrm{LC}$ : omega-3 long-chain polyunsaturated fatty acid, ${ }^{a} \mathrm{n}-6 / \mathrm{n}-3$ : ratio of omega- 6 polyunsaturated fatty acid to omega-3 polyunsaturated fatty acids, 'SFA I: saturated fatty acid intake relative to $10 \%$ of 2000 calorie intake, ${ }^{\mathrm{S}} \mathrm{ALA}$ I: alpha linoleic intake relative to $0.2 \%$ of 2000 calorie intake, ${ }^{\mathrm{t}} \mathrm{n}-3 \mathrm{I}$ : total omega-3 fatty acid intake relative to $0.5 \%$ of 2000 calorie intake, ${ }^{\mathrm{n}} \mathrm{n}-3 \mathrm{LC}$ I: long-chain omega-3 fatty acid intake relative to $250 \mathrm{mg}$.

Fatty acid intakes across rows without the same superscript differ significantly $(p<0.05)$ according to Tukey's honesty test 